\title{
RESEARCH
}

Open Access

\section{OCT4 maintains self-renewal and reverses senescence in human hair follicle mesenchymal stem cells through the downregulation of p21 by DNA methyltransferases}

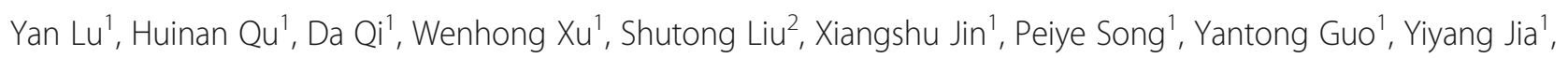
Xinqi Wang ${ }^{1}$, Hairi Li ${ }^{3}$, Yulin Li ${ }^{1}$ and Chengshi Quan ${ }^{1 *}$

\begin{abstract}
Background: Self-renewal is dependent on an intrinsic gene regulatory network centered on OCT4 and on an atypical cell cycle G1/S transition, which is also regulated by OCT4. p21, a gene negatively associated with selfrenewal and a senescence marker, is a member of the universal cyclin-dependent kinase inhibitors (CDKIs) and plays critical roles in the regulation of the G1/S transition. The expression of p21 can be regulated by OCT4-targeted DNA methyltransferases (DNMTs), which play distinct roles in gene regulation and maintaining pluripotency properties. The aim of this study was to determine the role of OCT4 in the regulation of self-renewal and senescence in human hair follicle mesenchymal stem cells (hHFMSCs) and to characterize the molecular mechanisms involved.

Methods: A lentiviral vector was used to ectopically express OCT4. The influences of OCT4 on the self-renewal and senescence of hHFMSCs were investigated. Next-generation sequencing (NGS) was performed to identify the downstream genes of OCT4 in this process. Methylation-specific PCR (MSP) analysis was performed to measure the methylation level of the p21 promoter region. p21 was overexpressed in hHFMSCs ${ }^{\text {OCT4 }}$ to test its downstream effect on OCT4. The regulatory effect of OCT4 on DNMTs was examined by ChIP assay. 5-aza-dC/zebularine was used to inhibit the expression of DNMTs, and then self-renewal properties and senescence in hHFMSCs were detected.

Results: The overexpression of OCT4 promoted proliferation, cell cycle progression, and osteogenic differentiation capacity of hHFMSCs. The cell senescence of hHFMSCs was markedly suppressed due to the ectopic expression of OCT4. Through NGS, we identified 2466 differentially expressed genes (DEGs) between hHFMSCs ${ }^{\text {OCT4 }}$ and hHFMSCs ${ }^{\text {EGFP }}$, including p21, which was downregulated. The overexpression of p21 abrogated the proliferation and osteogenic differentiation capacity of hHFMSCS ${ }^{\text {OCT4 }}$ and promoted cell senescence. OCT4 enhanced the transcription of DNMT genes, leading to an elevation in the methylation of the p21 promoter. The inhibition of DNMTs reversed the OCT4-induced p21 reduction, depleted the self-renewal of hHFMSCs ${ }^{\text {OCT4 }}$, and triggered cell senescence.
\end{abstract}

Conclusions: OCT4 maintains the self-renewal ability of hHFMSCs and reverses senescence by suppressing the expression of p21 through the upregulation of DNMTs.

Keywords: hHFMSCs, OCT4, Self-renewal, Senescence, p21, DNMTs

\footnotetext{
* Correspondence: quancs1@163.com

${ }^{1}$ The Key Laboratory of Pathobiology, Ministry of Education, Department of

Pathology, College of Basic Medical Sciences, Jilin University, 126 Xinmin

Avenue, Changchun 130021, China

Full list of author information is available at the end of the article
}

(c) The Author(s). 2019 Open Access This article is distributed under the terms of the Creative Commons Attribution 4.0 International License (http://creativecommons.org/licenses/by/4.0/), which permits unrestricted use, distribution, and

reproduction in any medium, provided you give appropriate credit to the original author(s) and the source, provide a link to the Creative Commons license, and indicate if changes were made. The Creative Commons Public Domain Dedication waiver (http://creativecommons.org/publicdomain/zero/1.0/) applies to the data made available in this article, unless otherwise stated. 


\section{Background}

As a regenerative organ, hair follicles are characterized by periodic growth and constant self-renewal [1]. Dermal sheath cells and dermal papilla cells in the hair follicles share a similar stemness to bone marrow mesenchymal stem cells [2]. Human hair follicle mesenchymal stem cells (hHFMSCs) express relatively specific surface markers of mesenchymal stem cells (MSCs) and have the potential to differentiate into osteoblasts, adipocytes, and chondrocytes [3]. Due to the abundance of supplies, safe access, and low immunogenicity [4], hHFMSCs are considered to be a promising source of cells for the rapidly emerging field of regenerative medicine and to be particularly beneficial for personalized cell therapy. However, hHFMSCs alter their biological properties and enter into a state of replicative senescence after a certain period of cell culture. Thus, fully understanding the molecular mechanisms involved in the regulation of hHFMSC selfrenewal and senescence (i.e., maintaining stem cell properties) would provide a great advancement in the application of these cells. The regulation of stem cell self-renewal and its properties resides in conserved transcriptional regulatory networks $[5,6]$ and epigenetic modifications, such as DNA methylation, that work together to repress developmental genes and activate stemness genes [7].

OCT4 (also known as POU domain transcription factor, Pou5f1) is the most upstream gene in the signaling pathway that regulates the self-renewal of stem cells [8]. OCT4, downregulated after cell differentiation [9], maintains cell self-renewal in the absence of feeder cells in human and mouse embryonic stem cells (ESCs) [10]. The abrogation of OCT4 in ESCs leads to cell differentiation [11-13]. OCT4, SOX2, and NANOG are wellknown key components of the core regulatory network that governs stem cells/pluripotency, whereas epigenetic regulators also play important roles in maintaining pluripotency $[14,15]$. Moreover, NANOG expression is directly regulated by OCT4 and SOX2 [16]. The phenotypes of SOX2-null cells can be rescued by ectopic expression of wild-type levels of OCT4 [17]. Therefore, OCT4 is considered to be the paramount transcription factor (TF) in the establishment and maintenance of pluripotency. There is a strong inverse correlation between the expression of OCT4 and senescence [18]. OCT4 is also a cell cycle promoter, which removes the blockage of cell cycle progression in the $\mathrm{G} 1$ phase and stimulates the entry into the $S$ phase [19]; this is a unique cell cycle structure that is required by self-renewal capacity $[20,21]$.

It has been well characterized that the G1/S transition is mainly regulated by G1 regulatory molecules [22]. Among these regulatory molecules, p21 is a member of the universal cyclin-dependent kinase inhibitors (CDKIs) and plays critical roles in the regulation of the G1/S transition [23]. p21 mediates cell quiescence in neural [24] and hair follicle stem cells [25]. The knockdown of p21 enhances the proliferation, expression of stemness markers, and osteogenic potential in human MSCs [26]. It was reported that the gene transcription level of p21 was regulated by DNA methylation because the $\mathrm{p} 21$ promoter contained a high density of potentially methylatable CpG dinucleotide clusters [27].

DNA methylation is a heritable chemical modification of the DNA molecule, is predominantly associated with transcriptional repression, and is essential for mammalian development [28]. DNA methyltransferases (DNMTs) lead to the ectopic methylation of DNAs, leading to gene silencing. DNA methyltransferase 3 alpha (DNMT3a) and beta (DNMT3b) establish de novo methylation in early development [29]. Once established, methylation patterns are faithfully maintained by DNA methyltransferase 1 (DNMT1) following mitosis in cells [30]. It was reported that DNMT3a ${ }^{-1-}$ and DNMT3b ${ }^{-1-}$ double-knockout ESCs are fully viable and could be differentiated into all three germ layers [31, 32]. Interestingly, rapid downregulation of exogenous DNMT1 results in subsequent cell death. Thus, it seems that DNMT1 is essential to maintain the viability of hESCs [33]. DNA methylation plays multiple roles in developmental gene regulation in mammalian ESCs [34].

The present study investigated the role of OCT4 in maintaining the self-renewal ability of hHFMSCs and reversing senescence, and the mechanism involved p21 and DNMTs. These results support the application of hHFMSCs in regenerative medicine, particularly to benefit personalized cell therapy.

\section{Materials and methods}

\section{Cell culture and reagents}

hHFMSCs were isolated and identified as reported in our previous work [35]. hHFMSCs and transduced hHFMSCs (hHFMSCs ${ }^{\text {EGFP }}$ and hHFMSCs ${ }^{\text {OCT4 }}$ ) were cultured in H-DMEM/F12 (Gibco, Grand Island, NY, USA) medium supplemented with 10\% FBS (Gibco), $10 \mathrm{ng} / \mathrm{ml}$ bFGF (R\&D Systems, Minneapolis, MN, USA), and $100 \mathrm{U} / \mathrm{ml}$ penicillin-streptomycin (Hyclone, Logan, UT, USA). HEK293T cells were cultured in $\mathrm{H}$-DMEM (Gibco) supplemented with $10 \% \mathrm{FBS}$ at $37^{\circ}$ $\mathrm{C}$ and in the presence of $5 \% \mathrm{CO}_{2}$. The following antibodies were used: anti-OCT4, anti-DNMT1, and antiKi67 antibodies (Abcam, Cambridge, MA, USA); antiDNMT3a, anti-p21, anti-proliferating cell nuclear antigen (PCNA), and anti-Cyclin D1 antibodies (Cell Signaling Technology, Beverly, MA, USA); and antiDNMT3b antibody (Thermo Fisher Scientific, Waltham, MA, USA). 5-aza-dC and zebularine were purchased from Sigma-Aldrich (St. Louis, MO, USA). 
Lentivirus production and lentivirus transduction

The lentiviral vectors pLV-EF1 $\alpha$-IRES-EGFP and pLVEF1 $\alpha$-OCT4-IRES-EGFP and the packaging plasmids expressing gag-pol, pVSVG, and rev genes were obtained from the Institute of Biochemistry and Cell Biology of Shanghai Life Science Research Institute, Chinese Academy of Sciences. These vectors were transfected into 293T cells by X-tremeGene HP DNA Transfection Reagent (Roche Applied Science, Rotkreuz, CH). Viral supernatants were harvested at $48 \mathrm{~h}$ and $72 \mathrm{~h}$ after transfection and concentrated by ultracentrifugation. hHFMSCs-P15 $\left(1 \times 10^{4} /\right.$ well $)$ were seeded on Matrigelcoated 12-well plates, and cells were infected with lentivirus in the presence of $8 \mu \mathrm{g} / \mathrm{ml}$ polybrene (Santa Cruz, CA, USA) for $24 \mathrm{~h}$.

After transduction, live cells were identified by 7-amino actinomycin (7AAD, KeyGEN BioTECH, Nanjing, China) exclusion and analyzed for GFP expression on a BD FACSCalibur flow cytometer (BD Biosciences, San Jose, CA, USA) to detect transduction efficiency.

\section{Real-time fluorescence quantitative polymerase chain reaction (RT-qPCR)}

Total RNA was isolated by TRIzol Reagent (Invitrogen Life Technologies, NY, USA). RNA was then subjected to cDNA synthesis using M/MLV kit (TAKARA, Osaka, Japan). RT-qPCR was performed with an ABI 7300 realtime PCR system (Applied Biosystems, Foster City, CA, USA), and samples were normalized to GAPDH with the autoset baseline. qPCR was conducted in triplicates using $25 \mathrm{ng}$ of reverse-transcribed cDNA and $0.2 \mu \mathrm{M}$ of primer in a $20 \mu \mathrm{l}$ final reaction volume containing $1 \times$ SYBR Premix EX Taq (TAKARA). Using comparative critical cycle $(\mathrm{Ct})$ method with GAPDH as an endogenous control, the relative expression was calculated as 2
$-\Delta \mathrm{Ct}$ and compared between two groups. Detailed information on these primers is listed in Table 1.

\section{Western blotting analysis}

Cells were harvested and lysed in $300 \mu \mathrm{l}$ ice-cold radioimmunoprecipitation assay lysis buffer supplemented with $1 \%$ phenylmethylsulfonyl fluoride and then centrifuged at $12,000 \mathrm{~g}$ at $4{ }^{\circ} \mathrm{C}$ for $30 \mathrm{~min}$ to remove cell debris. Protein concentration was determined by using a BCA Protein Assay Kit (Pierce Chemical Co., Rockford, IL, USA). Cell lysates were separated on 10\% SDS-PAGE and then transferred onto a nitrocellulose membrane (Millipore, Temecula, CA, USA). The membrane was incubated with $5 \%$ nonfat milk (Applichem) at $37^{\circ} \mathrm{C}$ for 1 $\mathrm{h}$ and then incubated with primary antibodies at $4{ }^{\circ} \mathrm{C}$ overnight and secondary antibodies conjugated to horseradish peroxidase for $1 \mathrm{~h}$ under the room temperature. The membranes were finally stained with an ECL Western blotting system (GE, Fairfield, CT, USA).

\section{Immunofluorescence}

Cells were fixed in 4\% paraformaldehyde (Ding Guo, Beijing, China) for $10 \mathrm{~min}$ and permeabilized with $0.1 \%$ Triton X-100 (Sigma, St. Louis, USA) for 20 min under the room temperature. One percent BSA/PBS was used to block nonspecific binding. Cells were then incubated overnight with primary antibodies (OCT4 and Ki67, $1: 500)$ at $4{ }^{\circ} \mathrm{C}$. The secondary antibody was Alexa Fluor 647 anti-rabbit IgG (1:200 dilution; CST). The nuclei were counterstained with $5 \mu \mathrm{g} / \mathrm{ml}$ DAPI (Sigma-Aldrich) for $2 \mathrm{~min}$ in the dark, and cells were visualized with a laser scanning confocal microscope (Olympus, Tokyo, Japan).

Table 1 Primers for qPCR, ChIP, and MSP

\begin{tabular}{|c|c|c|}
\hline Gene & Forward primers ( $5^{\prime}$ to $3^{\prime}$ ) & Reverse primers ( $5^{\prime}$ to $\left.3^{\prime}\right)$ \\
\hline OCT4 & CTGAAGCAGAAGAGGATCAC & GACCACATCCTTCTCGAGCC \\
\hline p21 & TGGAGACTCTCAGGGTCGAAA & GGCGTTGGAGTAGAAATC \\
\hline p16 & GTGGACCTGGCTGAGGAG & CाTTCAATCGGGGATGTCTG \\
\hline hTERT & CATGGGCACGTCCGCAA & GGCGTGGTGGCACATGAA \\
\hline DNMT1 & ACCGCTTCTACTTCCTCGAGGCCTA & GTTGCAGTCCTCTGTGAACACTGTGG \\
\hline DNMT3a & CACACAGAAGCATATCCAGGAGTG & AGTGGACTGGGAAACCAAATACCC \\
\hline DNMT3b & AATGTGAATCCAGCCAGGAAAGGC & ACTGGATTACACTCCAGGAACCGT \\
\hline GAPDH & CCATGTTCGTCATGGGTGTGA & CATGGACTGTGGTCATGAGT \\
\hline DNMT1 (ChIP) & CCCCACACACTGGGTATAGAA & CGAGGCATTCATTCATTCATT \\
\hline DNMT3a (ChIP) & TCATTCATTCAACCTCCCAC & СTCTGAGATGAGCTGCCTTGA \\
\hline DNMT3b (ChIP) & CATCCAAAGAATTAACCCTTCACT & GGTCTCCAAGTGCTTATAGTGGAT \\
\hline p21 U (MSP) & TाTGGGATTGGTTGGTाTG & ACACCCAACTCCAACTCCAC \\
\hline p21 M (MSP) & TTGTAGTACGCGAGGTTTCG & CAACTCAACGCGACCCTAAT \\
\hline
\end{tabular}




\section{Flow cytometry}

Cells were trypsinized and counted. Approximately $1 \times$ $10^{6}$ cells were used for the test. Cells were rinsed with PBS by centrifugation at $4{ }^{\circ} \mathrm{C}$, resuspended with $1 \%$ bovine serum albumin (BSA; Roche Diagnostics, Mannheim, Germany) in PBS, and incubated for $30 \mathrm{~min}$. Next, the cells were incubated with primary antibody rabbit anti-OCT4 (1:100) for $30 \mathrm{~min}$ on ice, followed by incubation with the Alexa Fluor 647-conjugated secondary antibody for $30 \mathrm{~min}$. The labeled cells were thoroughly washed with PBS and analyzed on a BD FACSCalibur flow cytometer. The primary antibody was omitted as a negative control.

\section{Cell proliferation analysis}

\section{iCELLigence cell proliferation analysis}

Cells were seeded at a density of 1500 cells/well into E-Plate 8 (ACEA Biosciences, Inc., San Diego, CA) containing $450 \mu \mathrm{l}$ medium per well and monitored for 7 days at $37^{\circ} \mathrm{C}$ in a $5 \% \mathrm{CO}_{2}$ atmosphere, with one change of fresh medium at day 4. Dynamic monitoring of the growth pattern was determined by the impedancebased iCELLigence system (Roche Applied Science, Germany). The cell index was derived from measured cell-electrode impedance that correlates with the number of cells and viability.

\section{Population doubling time $=t \times\left\{\lg 2 /\left(\lg N_{t}-\lg N_{o}\right)\right\}$}

Cells were seeded in 24-well plates at a low density (5000 cells/well) and cultured as described above. The number of cells was counted every $24 \mathrm{~h}$ through the following 7 days. Three replicate counts were performed in each of three independent experiments $(t$, incubation time; $N_{t}$, cell number after culturing for $t$ days; $N_{0}$, cell number of starting time).

\section{Cell Counting Kit-8 (CCK8) assay}

One hundred microliters cell suspensions (1000 cells/ well) was dispensed in 96-well plates and monitored for 7 days at $37^{\circ} \mathrm{C}$ in a $5 \% \quad \mathrm{CO}_{2}$ atmosphere, with one change of fresh medium at day 4. Following the treatment with 5 -aza-dC at the concentrations of $100 \mu \mathrm{M}$ for $72 \mathrm{~h}$, or with $100 \mu \mathrm{M}$ Zebularine for $48 \mathrm{~h}, 10 \mu \mathrm{l}$ CCK8 (Roche Diagnosis, Mannheim, Germany) was added to each well and incubated for $2 \mathrm{~h}$. The absorbance at 450 $\mathrm{nm}$ (A450) was examined with a scanning multi-well spectrophotometer (TECAN, CH).

\section{Colony formation assay}

hHFMSCs EGFP and hHFMSCs OCT4 cells were seeded into 6-well plates in a cell density of 20 cells $/ \mathrm{cm}^{2}$, and they were allowed to grow for 5 to 7 days until clones were visible. PBS-washed cells were fixed with $4 \%$ paraformaldehyde and then stained with Giemsa. The stained clones were counted, and the rate of clone's formation was calculated as follows: (number of stained clones/ number of seeded cells) $\times 100 \%$.

\section{Sphere formation assay}

Single cells were plated in ultra-low 6-well attachment plates (Corning, Lowell, MA, USA) at a density of 500 cells $/ \mathrm{cm}^{2}$ in H-DMEM/F12 medium, supplemented with $1 \%$ penicillin/streptomycin, B27 (1:50, Invitrogen, Life Technologies Corp, Carlsbad, CA, USA), $5 \mu \mathrm{g} / \mathrm{ml}$ insulin (R\&D Systems), $20 \mathrm{ng} / \mathrm{ml}$ epidermal growth factor (R\&D Systems), and $20 \mathrm{ng} / \mathrm{ml}$ bFGF. After 5 days, sphere formation was assessed by counting the number of clonal spheres (cells > 3) under an optical microscope.

\section{Cell cycle assay}

Cells were plated in 6 -cm-diameter dishes $\left(3 \times 10^{5}\right.$ cells/ dish) and allowed to grow for 3 days. The cell cycle status was determined by the Cell Cycle Detection Kit (KeyGEN BioTECH). Briefly, cells were collected and washed with cooled PBS, fixed and permeabilized, treated with RNase A and stained with a PI solution, and then observed at $488 \mathrm{~nm}$ of excitation wavelength by flow cytometry and photographed.

$$
\begin{aligned}
\text { Proliferation index }(\mathrm{PI})= & (\mathrm{S}+\mathrm{G} 2) /(\mathrm{G} 1+\mathrm{S}+\mathrm{G} 2) \\
& \times 100 \% .
\end{aligned}
$$

\section{Osteogenic differentiation}

Cells were cultured in the osteogenic medium (high glucose-DMEM, $10 \%$ FBS, $50 \mu \mathrm{M}$ ascorbate-2-phosphate, $0.1 \mu \mathrm{M}$ dexamethasone, $10 \mathrm{mM} \beta$-glycerolphosphate) for 2 weeks. Following the differentiation, Alizarin Red staining was performed to examine osteogenic differentiation.

\section{Transmission electron microscopy}

$5 \times 10^{7}$ cells were rinsed with PBS and fixed for $30 \mathrm{~min}$ with $2.8 \%$ glutaraldehyde at room temperature. After rinsing twice, the specimens were post-fixed for $60 \mathrm{~min}$ with $2 \%$ osmium tetroxide in cacodylate buffer. The cells were then dehydrated in the increasing ethanol concentrations (40,50, 70, 85, 90, 95, and 100\%) and covered twice for $3 \mathrm{~h}$ with a thin layer of Araldite 502 resin (for ethanol substitution). Finally, the resin was allowed to polymerize at $60^{\circ} \mathrm{C}$ for $48 \mathrm{~h}$. The specimens were detached from the plastic vessels, inverted in embedding molds, covered with Araldite 502, and re-incubated at $60{ }^{\circ} \mathrm{C}$ for $48 \mathrm{~h}$. The thin sections were prepared with an ultra-microtome (LKB-III, Sweden), contrasted with lead citrate and uranyl acetate, and observed in a blind fashion with a transmission electron microscope (Hitachi, JEM-1200EX, Japan). Each test was repeated three times. 
All reagents were purchased from Electron Microscopy Sciences (Cedarlane, Hornby, Ontario).

Senescence-associated $\beta$-galactosidase (SA- $\beta$-gal) staining Cells were seeded in 6-well plates with a density of $1 \times$ $10^{5}$ cells/well. After cultured for $24 \mathrm{~h}$, the cells were stained by SA- $\beta$-gal to detect cell senescence by using the SA- $\beta$-gal kit (Beyotime, Beijing, China) as described in the instruction of the manufacturer. The senescent cells were observed with an optical microscope and counted in five random fields of vision.

\section{Next-generation sequencing}

The expression profile of mRNA (hHFMSCs ${ }^{\text {OCT4 }}$ and hHFMSCs ${ }^{\text {EGFP }}$ ) was determined by next-generation sequencing (NGS). Total RNA from harvested cells was extracted by Trizol $^{\circ}$ Reagent (Invitrogen, USA) according to the manufacturer's instructions. RNA quality and concentration were measured by using a NanoDrop spectrophotometer (Thermo Fisher Scientific, MA, USA) before further processing. Then RNA samples were shipped to the University of California (University of California, San Diego, CA, USA) for sequencing. The quality of extracted RNA was confirmed by using Agilent Bioanalyzer (Agilent Technology, USA) (RNA integrity number $(\mathrm{RIN})>8$ ). After purification, the pooled libraries were loaded in eight lanes of flow cells and sequenced on a HiSeq 2500 (Illumina, Inc., San Diego, CA, USA) with V4 sequencing reagents. The reads were mapped to the human reference genome GRCh38/hg38 using Bowtie2. The expression values were calculated by using RSEM [36] for each gene (Ensembl, Homo.sapiens.GRCh38.87.gtf) in individual samples. Differential expression was analyzed between different subgroups using edgeR [37]. The criteria for differentially expressed mRNAs were set at a fold change of more than 2.0. Differential expression was analyzed between different subgroups using edgeR. Data were clustered and visualized using Cluster and Java TreeView.

\section{Gene ontology (GO) and Kyoto Encyclopedia of Genes and Genomes (KEGG) pathway mapping analysis}

The Database for Annotation, Visualization and Integrated Discovery (DAVID) database [38] was used to analyze the differentially expressed genes between hHFMSCs $^{\text {EGFP }}$ and hHFMSCs ${ }^{\text {OCT4 }}$. The potential targets of differentially expressed genes were analyzed by the GO program, and enriched pathways were analyzed by the KEGG program. The GO analysis included biological process (BP), molecular function (MF), and cellular component (CC) terms, and $p<0.01$ was regarded as statistically significant. The enriched pathways were analyzed by the KEGG program, and enriched pathways were identified according to $p<0.01$ and FDR $<0.05$.

\section{Chromatin immunoprecipitation (ChIP) assay}

ChIP assays were performed with the EZ Magna ChIP G Chromatin Immunoprecipitation kit (Millipore, Billerica, MA, USA) using chromatin isolated from $1 \times 10^{6}$ cells per condition, according to the manufacturer's protocol. The anti-OCT4 (1:500) and anti-IgG (Millipore, as a negative control) antibodies were included. The specific primers for the promoter fragments of DNMT1, DNMT3a, and DNMT3b are listed in Table 1.

\section{Methylation-specific PCR (MSP) analysis}

MSP based on bisulfite conversion was performed. Genomic DNA from cells was isolated using the DNA extraction kit (Qiagen, Valencia, CA, USA), and the MethylEdge $^{\text {Tax }}$ Bisulfite Conversion System (Promega, Madison, WI, USA) was used for sodium bisulfite treatment of the genomic DNA according to the manufacturer's protocol. The MSP primers for p21 are listed in Table 1.

\section{Immunocytochemistry}

Cells were seeded on glass slides in 24-well plates at a density of 5000 cells/well and were fixed in $4 \%$ paraformaldehyde at room temperature (RT) for $10 \mathrm{~min}$. Immunocytochemistry staining was performed using a standard immunoperoxidase staining procedure (primary antibody to Ki67 antibody 1:500 Abcam). Hematoxylin was used as a counterstain.

\section{Statistical analysis}

All numerical data are means \pm SEM. Data were analyzed with a two-tailed $t$ test followed by ANOVA (GraphPad Prism, San Diego, CA). The results were considered significant at $p<0.05$.

\section{Results}

Establishment of the hHFMSC cell line with ectopic expression of OCT4 (hHFMSCs ${ }^{\text {OCT4 }}$ )

The proliferation, cell cycle, and differentiation potential were inhibited in hHFMSCs, and they entered into a state of replicative senescence after a certain length of cell culture (Additional file 1: Figure S1 \& S2). To determine the role of OCT4 in the maintenance of hHFMSC stem cell properties, hHFMSCs were plated on Matrigelcoated dishes and infected with lentiviruses encoding OCT4 or GFP (a scramble control). Hereafter, hHFMSCs infected with scrambled lentiviruses are referred to as hHFMSCs ${ }^{\text {EGFP }}$, and hHFMSCs transduced with lentiviruses encoding OCT4 are referred to as hHFMSCs ${ }^{\text {OCT4 }}$. The morphology of hHFMSCs ${ }^{\text {OCT4 }}$ was changed after transduction compared with that of hHFMSCs ${ }^{\text {EGFP }}$. Cell size gradually decreased from day 0 to day 10 , and original spindle-shaped cells were changed to polygonal or cobblestone-like cells (Fig. 1a). After 14 days, 80.08\% 
a
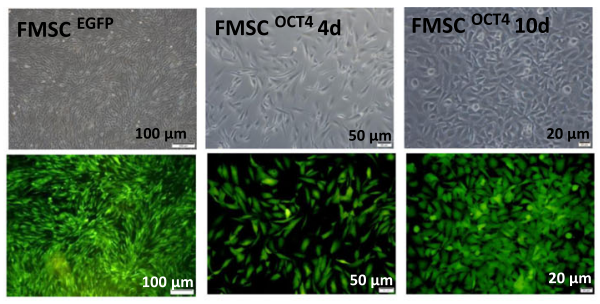

b

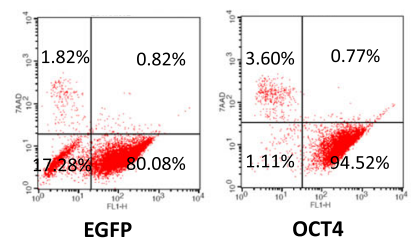

e

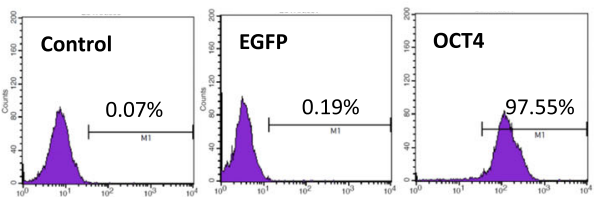

C
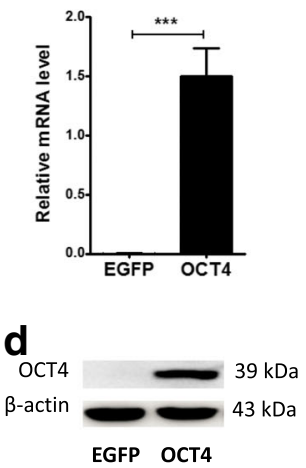

f

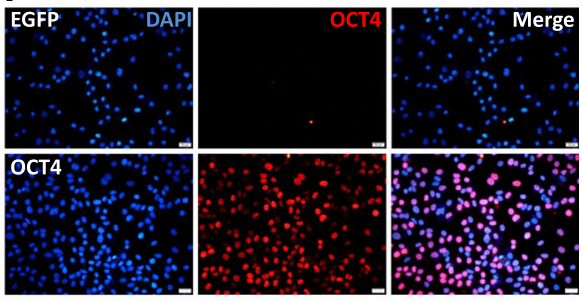

Fig. 1 The validation of the fluorescence efficiency and the expression of OCT4 in transduced hHFMSCs. a The cell morphologies of transduced hHFMSCs (hHFMSCs ${ }^{\text {EGFP }}$ and hHFMSCs ${ }^{\text {OCT4 }}$ ) were changed between 0 and 10 days after OCT4 transduction. b Flow cytometry assay of GFP expression in hHFMSCs after 12 days of transduction. Live cells were identified by 7AAD exclusion. qPCR (c), western blot (d), and flow cytometry (e) results for the

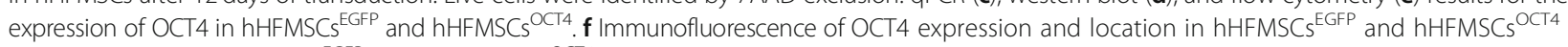
(bar, $20 \mu \mathrm{m})\left(\right.$ EGFP, hHFMSCs ${ }^{\text {EGFP }}$; OCT4, hHFMSCs ${ }^{\text {OCT4 }} ;{ }^{* *} p<0.01$ )

of the hHFMSCs ${ }^{\text {EGFP }}$ cells and $94.52 \%$ of the hHFM $\mathrm{SCs}^{\text {OCT4 }}$ cells remained $\mathrm{GFP}^{+}$(Fig. 1b), suggesting a high transduction efficiency. The expression of OCT4 was further confirmed by qPCR (Fig. 1c), western blot (Fig. 1d), and flow cytometry analysis (Fig. 1e). The expression of OCT4 was markedly higher in hHFMSCs ${ }^{\text {OCT4 }}$ than in control cells. The latter expressed a low level of endogenous OCT4. Immunofluorescence staining showed that OCT4 was located in the nuclei of the cells (Fig. 1f). Thus, we established a hHFMSC cell line, hHFMSCs ${ }^{\text {OCT4 }}$, with ectopic expression of OCT4.

\section{Expression of OCT4 leads to the increased proliferative capacity, cell cycle progression, and osteogenic differentiation in hHFMSCs}

To examine the effect of OCT4 on hHFMSC proliferation, an iCELLigence cell proliferation assay was performed. The cell growth rate over a 7-day period was significantly increased in hHFMSCs ${ }^{\text {OCT4 }}$ compared with that of hHFMSCs ${ }^{\text {EGFP }}$ (Fig. 2a). A shorter population doubling time was observed in hHFMSCs ${ }^{\text {OCT4 }}$ (Fig. 2b). Colony formation was significantly higher in hHFM $\mathrm{SCs}^{\text {OCT4 }}$ than in hHFMSCs ${ }^{\text {EGFP }}$. hHFMSC ${ }^{\text {EGFP }}$ clones exhibited scattered phenotypes, whereas hHFMSC ${ }^{\text {OCT4 }}$ clones were relatively compacted (Fig. 2c). Sphere formation assays showed that the number and size of the spheres were significantly larger in hHFMSCs ${ }^{\text {OCT4 }}$ (Fig. 2d). The expression of the proliferation-associated proteins PCNA, Cyclin D1, and Ki67 was upregulated in hHFMSCs ${ }^{\text {OCT4 }}$ compared with that of hHFMSCs ${ }^{\text {EGFP }}$ (Fig. 2e, f).

To further clarify the influence of OCT4 on the cell cycle and proliferation, the percentage of cells in G1, $\mathrm{G} 2$, and $\mathrm{S}$ phases and the proliferative index (PI) of hHFMSCs ${ }^{\text {OCT4 }}$ were compared with those of the control hHFMSCs ${ }^{\text {EGFP }}$. As shown in Fig. 2g, hHFMSCs ${ }^{\text {OCT4 }}$ displayed a shortened G1 phase and an extended G2 and $S$ phases (Fig. 2g). There was also a higher PI in hHFMSCs $^{\text {OCT4 }}$ (Fig. 2g).

To demonstrate the effect of OCT4 on hHFMSC differentiation potential, an osteogenic differentiation assay was performed. The results demonstrated that the osteogenic differentiation capacity was markedly increased in hHFMSCs $^{\text {OCT4 }}$ (Fig. 2h). Taken together, our data suggest that the expression of OCT4 enhances the proliferative capacity of the hHFMSCs, expedites cell cycle progression, and promotes the hHFMSCs to differentiate into osteogenic cells.

\section{OCT4 reverses senescence in hHFMSCs}

To evaluate the impact of OCT4 on hHFMSC senescence, we analyzed the expression of the senescence-associated 


\section{a}

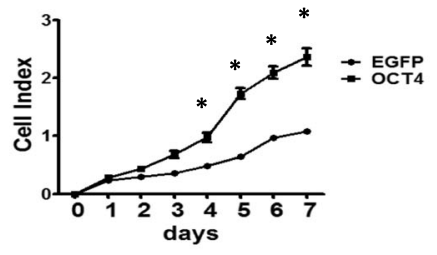

C EGFP

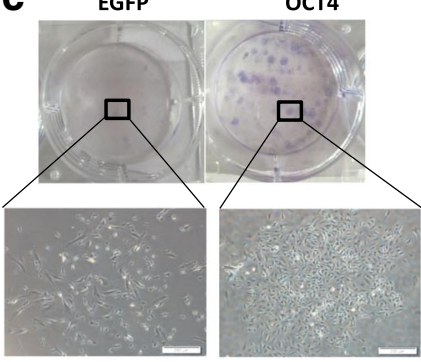

e

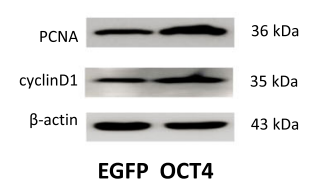

g
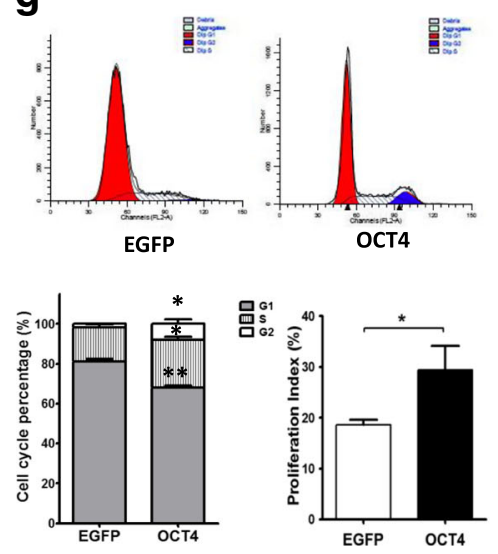

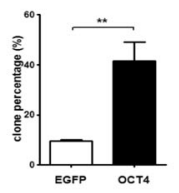

b

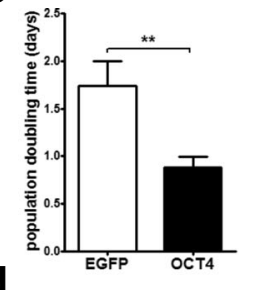

d
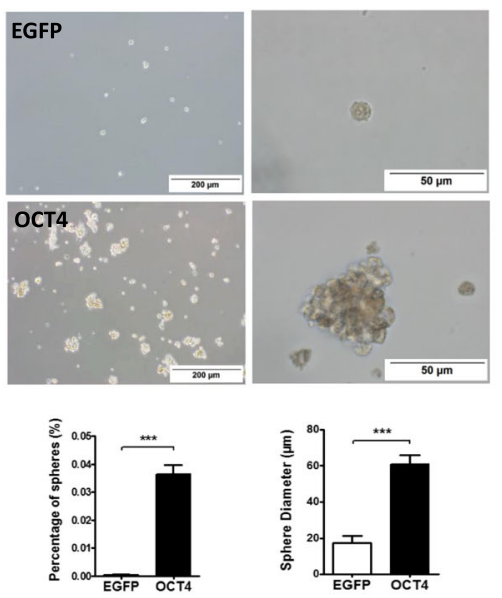

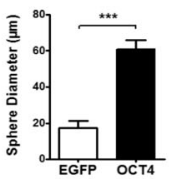

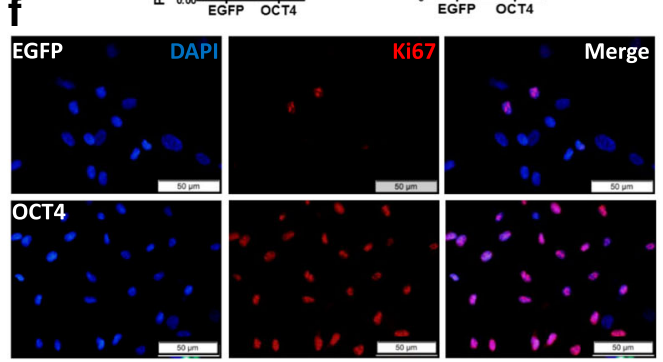

h

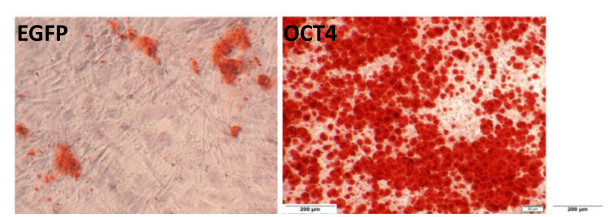

Fig. 2 OCT4 increased proliferation capacity and differentiation potential in hHFMSCs. Cell proliferation curve (a) and cell population doubling time (b) of hHFMSCs ${ }^{\text {EGFP }}$ and hHFMSCs ${ }^{\text {OCT4 }}$. c Clone formation assay of hHFMSCs ${ }^{\text {EGFP }}$ and hHFMSCs ${ }^{\text {OCT4 }}$; the enlarged views show the difference between the two cell clones. The histogram is the formation rate for each clone (bar, $200 \mu \mathrm{m})$. $\mathbf{d}$ Representative sphere images and bar graph of the percentages of spheres in hHFMSCS ${ }^{\text {EGP }}$ and hHFMSCS $^{\mathrm{OCT}}$. e Western blot results for the expression of proliferation-associated proteins PCNA and cyclin D1 in hHFMSCs ${ }^{\text {EFP }}$ and hHFMSCs ${ }^{\mathrm{OCT} 4}$. $\mathbf{f}$ Immunofluorescence of proliferation-associated protein Ki67 expression and location in hHFMSCs $^{\text {EGFP }}$ and hHFMSCs ${ }^{\text {OCT4 }}$ (bar, $50 \mu \mathrm{m}$ ). $\mathbf{g}$ Effects of OCT4 on hHFMSC cell cycle phase distribution. The percentage of the G1, G2, and S

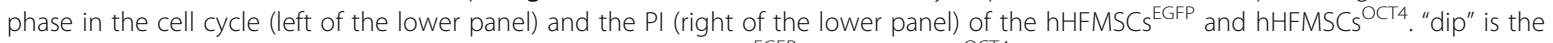
abbreviation for diploid. $\mathbf{h}$ Osteogenic differentiation in hHFMSCS ${ }^{\text {EFP }}$ and hHFMSCS ${ }^{\text {OCT4 }}$. Calcium nodules were detected by Alizarin Red S staining (bar, $200 \mu \mathrm{m}) .\left({ }^{*} p<0.05 ;{ }^{* *} p<0.01 ;{ }^{* * *} p<0.001\right)$

gene human telomerase catalytic subunit (hTERT), p21 and $\mathrm{p} 16$, the morphology, and the SA- $\beta$-gal staining of the cells. hTERT is a catalytic subunit of the enzyme telomerase, which promotes the elongation of the telomeres in stem cells, leading to the increased lifespan of stem cells by allowing for indefinite division without the shortening of telomeres and the inhibition senescence $[39,40]$. p21 coordinates cellular senescence by inducing cell cycle arrest [41]. p16 is expressed at high levels in senescing cells and plays a central role in the establishment of the senescent state [42]. qPCR showed that the expression of hTERT was upregulated, and the levels of p21 and p16 were downregulated in hHFMSCs ${ }^{\text {OCT4 }}$ compared with hHFMSCs ${ }^{\text {EGFP }}$ (Fig. 3a). Through the passages of 
a

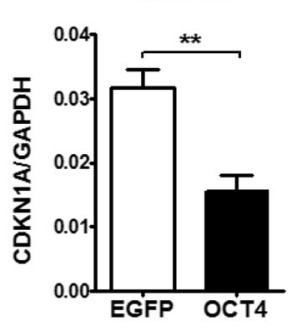

CDKN2A

hTERT
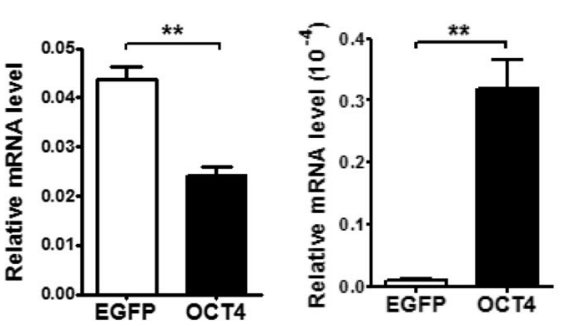

b
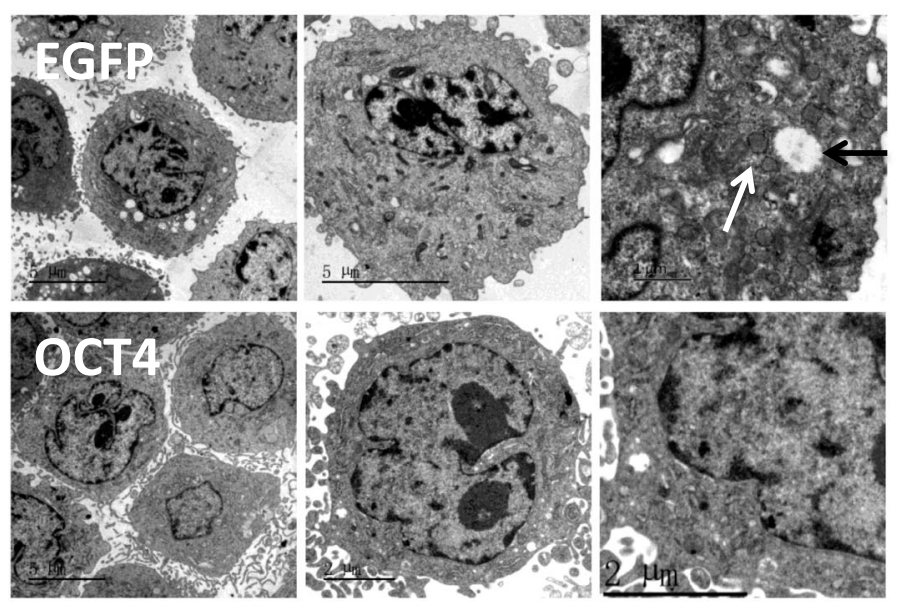

C
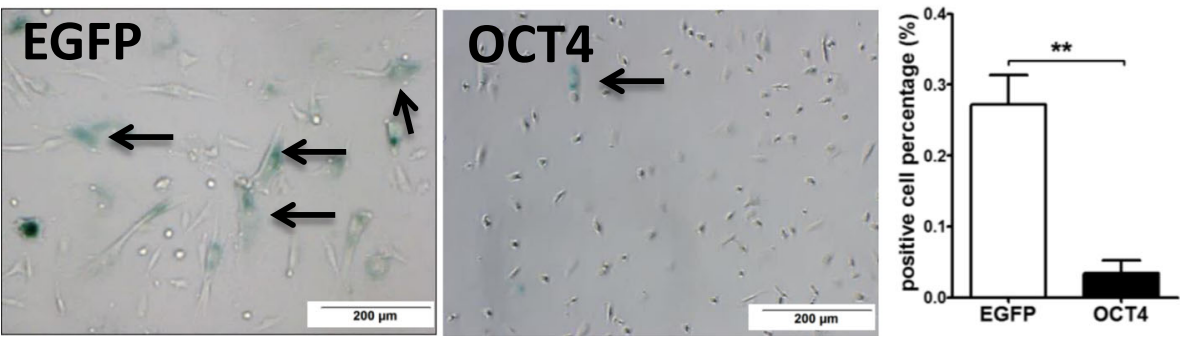

Fig. 3 OCT4 inhibited senescence in hHFMSCs. a qPCR results for the expression of senescence-associated genes. CDKN1A, p21; CDKN2A, p16. b Effects of OCT4 on hHFMSCs under transmission electron microscopy. White arrow, dilation of the rough endoplasmic reticulum; black arrow, turgidity and vacuolization of the mitochondrion. c SA- $\beta$-gal staining in hHFMSCs ${ }^{\text {EGFP }}$ and hHFMSCs ${ }^{\text {OCT4 }}$ (bar, $200 \mu$ m). Stained cells are indicated by arrows $(* * p<0.01)$

hHFMSCs ${ }^{\mathrm{EGFP}}$, transmission electron microscopy showed that microvilli on the cell surface were reduced, indicating a poor proliferation capacity (Fig. 3b) [43-45]. The endoplasmic reticulum in the cells was dilated, and the mitochondria were turgid and vacuolar (Fig. 3b). The nuclei became large and irregular in some cells. These data support our notion that hHFMSCs turned senescent during culture. In contrast, in hHFMSCs ${ }^{\mathrm{OCT} 4}$, the cells were enriched in microvilli throughout the entire cell surface, and the nuclei were regular in shape, containing a single nucleolus or multiple nucleoli. Euchromatin was abundant in the nucleus. The cytoplasm was enriched with rough endoplasmic reticulum, mitochondria, and glycogen granules. These data indicate that the vigorous proliferative status of hHFMSCs ${ }^{\mathrm{OCT} 4}$ was maintained. Furthermore, the SA- $\beta$-gal staining assay revealed that hHFMSCs ${ }^{\text {OCT4 }}$ possessed a strikingly lower level of SA- $\beta$-gal than hHFMSCs $^{\text {EGFP }}$ (Fig. 3c). Collectively, our data suggest that OCT4 maintains the proliferative status that delays hHFMSC senescence during culture.

\section{Identification of differentially expressed genes in hHFMSCs ${ }^{\text {OCT4 }}$ by next-generation sequencing}

To illustrate the potential molecular mechanisms by which OCT4 promotes self-renewal and reverses senescence in hHFMSCs, next-generation sequencing (NGS) was utilized. A total of 56,233 genes were analyzed, and 2466 differentially expressed genes (DEGs) were 
identified in hHFMSCs ${ }^{\text {OCT4 }}$ compared with hHFMSCs $^{\text {EGFP }}$. In the 2466 DEGs, 1181 were upregulated and 1285 were downregulated. We present 100 top DEGs, including 50 upregulated genes and 50 downregulated genes between hHFMSCs ${ }^{\text {EGFP }}$ and hHFMSCs ${ }^{\text {OCT4 }}$ and p21 (CDKN1A) in Fig. 4a. The details of the DEGs (Additional file 2) and the GO (Additional file 3: Table S1) and KEGG pathway (Additional file 3: Table S2) enrichment analyses are listed in the Additional files. Briefly, GO analysis results showed that the upregulated DEGs were significantly enriched in biological processes
(BPs) such as "DNA replication initiation," "DNA replication," and "G1/S transition of mitotic cell cycle"; the downregulated DEGs were highly enriched in BPs such as "extracellular matrix organization and cell adhesion" and "positive regulation of cell proliferation" (Fig. 4b). KEGG analysis showed that the upregulated DEGs were enriched in "cell cycle" and "protein digestion and absorption," while the downregulated DEGs were enriched in "proteoglycans in cancer," "pathways in cancer," "ECM-receptor interaction," "PI3K-Akt signaling pathway," "focal adhesion," and "regulation of actin cytoskeleton" (Fig. 4c).

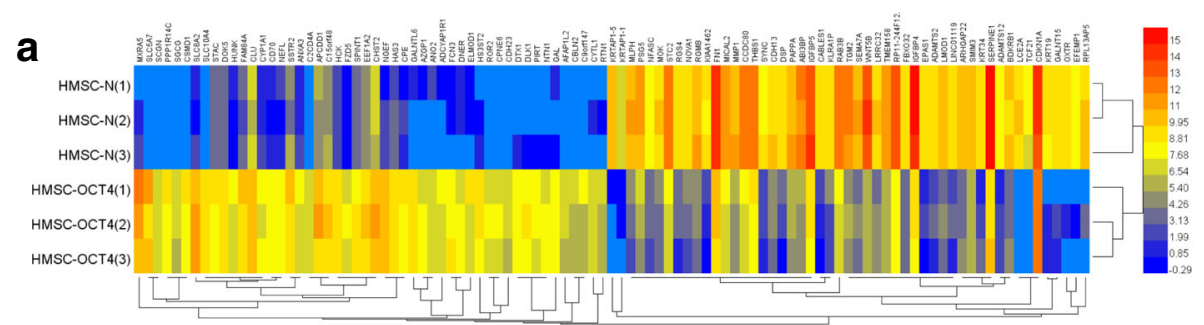

b

GO biological process of up-regulated DEGs

GO biological process of down-regulated DEGs
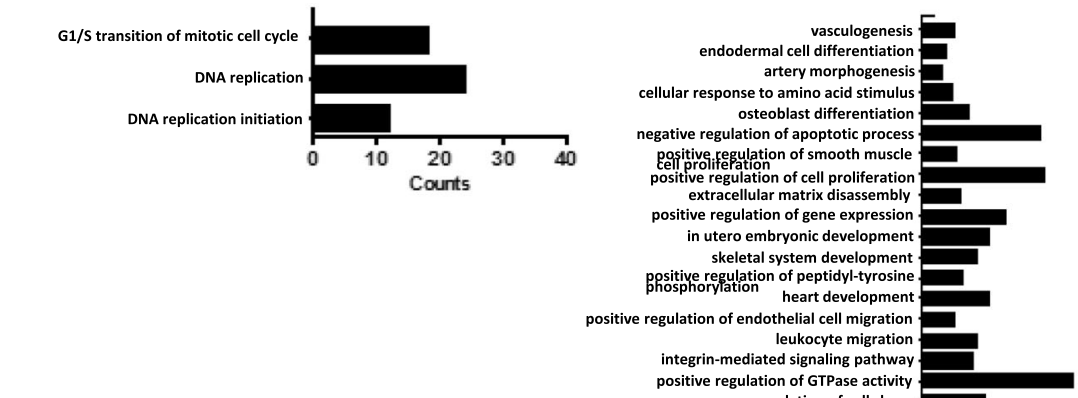

C KEGG pathway enrichment of up-regulated DEGs

hsa04974:Protein digestion and absorptionhsa04110:Cell cycle

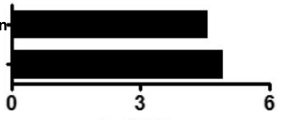

- $l o g$ PValue

KEGG pathway enrichment of down-regulated DEGs
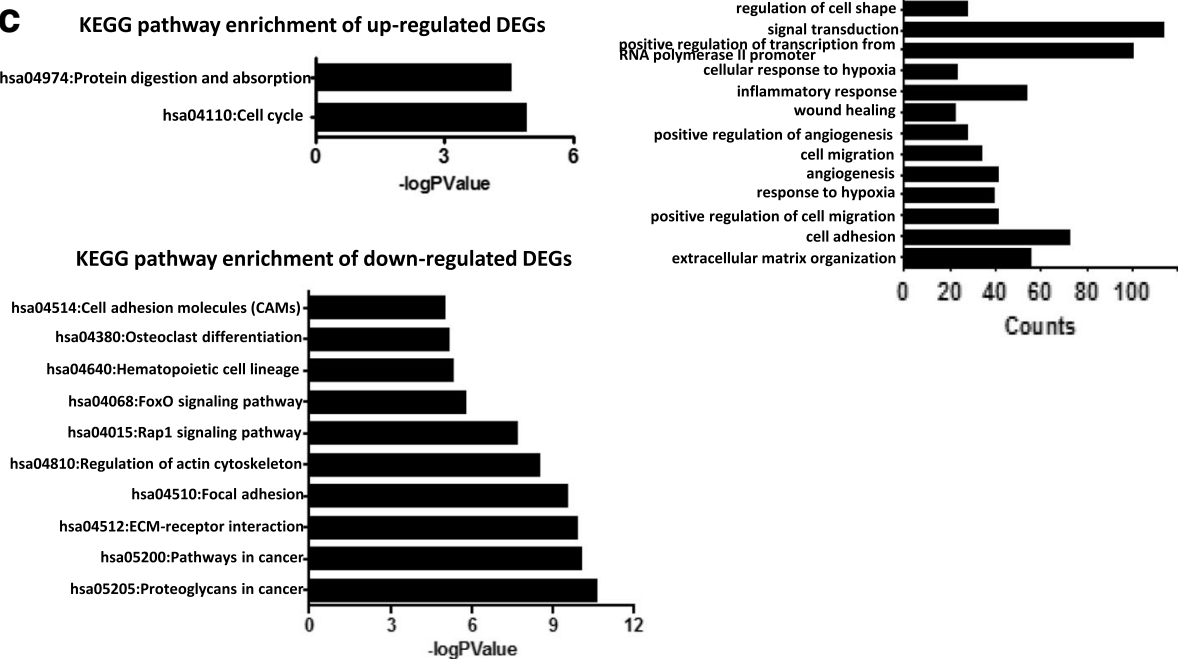

Fig. 4 Next-generation sequencing. a Heat map of the top 100 differentially expressed genes (50 upregulated genes and 50 downregulated genes) and P21 (CDKN1A) between hHFMSCs ${ }^{\text {EGFP }}$ and hHFMSCs ${ }^{\text {OCT4 }}$. Red, upregulation; blue, downregulation. b GO biological process analysis of the enrichment of differentially expressed genes between hHFMSCs ${ }^{\text {EGFP }}$ and hHFMSCs ${ }^{\text {OCT4 }}$. $\mathbf{c}$ KEGG analysis of the enrichment of differentially expressed genes between hHFMSCs ${ }^{\text {EGFP }}$ and hHFMSCs ${ }^{\text {OCT4 }}$ in specific pathways. GO, gene ontology; KEGG, Kyoto Encyclopedia of Genes and Genomes 
Thus, we conclude that OCT4 may maintain the self-renewal and reverse the senescence of hHFMSCs by regulating the comprehensive signaling pathways in cell biological processes. As p21 has been known to play a negative role in cell cycle signaling, we hypothesize that OCT4 maintains self-renewal and reverses senescence through p21.
The overexpression of p21 abolishes the effects of OCT4 on hHFMSCs

p21, which controls the cell entry into the cell cycle, was selected from NGS, as p21 was significantly downregulated in NGS (fold change $=2.807691, p=0.000751684$ ) . The downregulation of p21 was verified by qRT-PCR and western blot (Fig. 5a). As a gene negatively associated with self-renewal and a senescence marker, p21 plays critical roles in the regulation of the G1/S transition. Thus, we speculate that OCT4 may assist the a

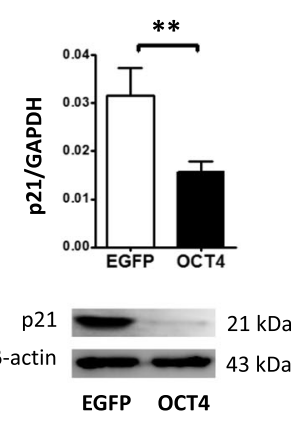

d

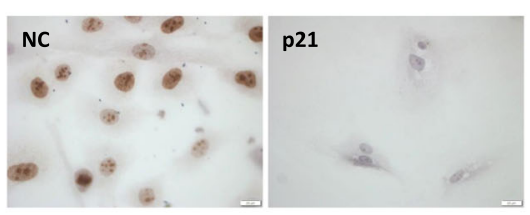

f
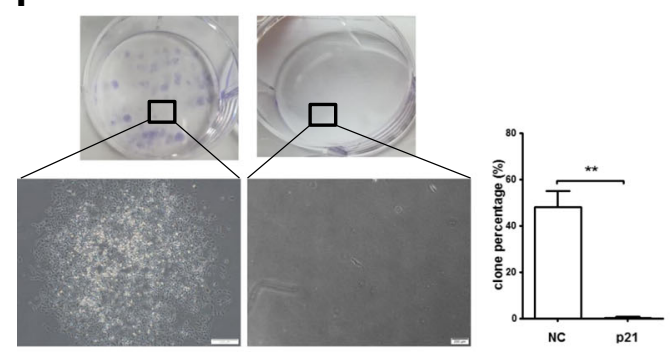

h

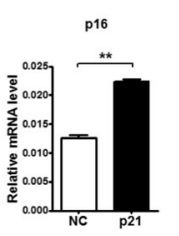

i

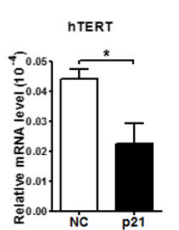

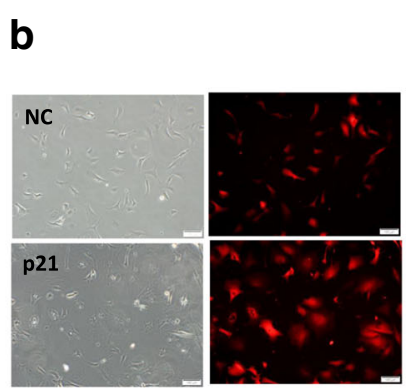
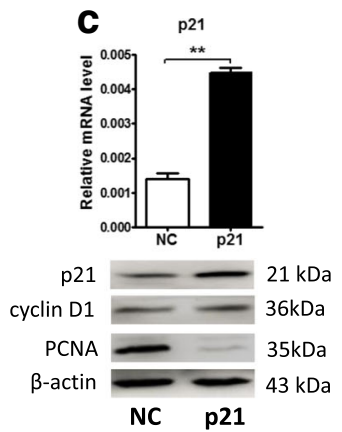

e

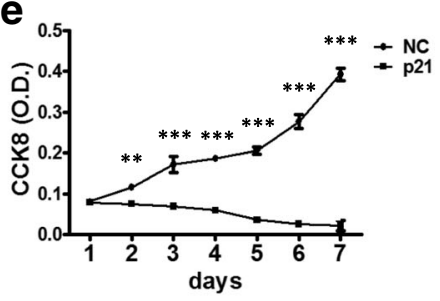

g

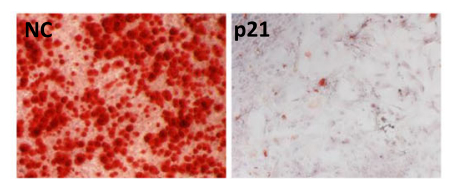

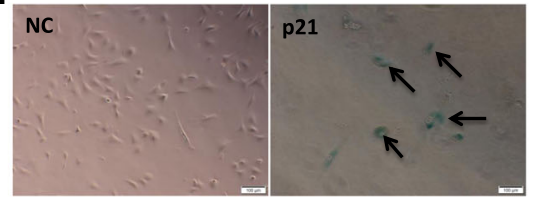

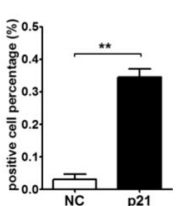

Fig. 5 The overexpression of p21 abolished the effect of OCT4 in hHFMSCS. a qPCR and western blot of the expression of p21 in hHFMSCs ${ }^{\text {EGFP }}$ and hHFMSCs ${ }^{\mathrm{OCT} 4}$. b The overexpression of $\mathrm{p} 21$ in hHFMSCs ${ }^{\mathrm{OCT} 4}$ (named NC and p21; bar, $100 \mu \mathrm{m}$ ). c qPCR and western blot after overexpressing p21. d Immunocytochemistry of Ki67 after overexpressing p21 (bar, $20 \mu \mathrm{m}$ ). Cell proliferation curve (e) and clone formation assay (f) after overexpressing p21; the enlarged views show the difference between the two cell clones. The histogram is the formation rates of the clones (bar, $200 \mu \mathrm{m}) . \mathbf{g}$ Osteogenic differentiation after overexpressing p21 in hHFMSCs ${ }^{\text {OCT4 }}$. Calcium nodules were detected by Alizarin Red S staining (bar, 200 um). h qPCR results for the expression of senescence-associated genes. i SA- $\beta$-gal staining after overexpressing p21 in hHFMSCs ${ }^{\text {OCT4 }}$ (bar, $200 \mu \mathrm{m}$ ). Stained cells are indicated by arrows $\left({ }^{*} p<0.05 ;{ }^{* *} p<0.01 ;{ }^{* * *} p<0.001\right)$ 
hHFMSCs to regain stemness through the downregulation of p21. To test this assumption, we overexpressed p21 in hHFMSCs ${ }^{\text {OCT4 }}$. As a result, cells with p21 overexpression became enlarged and flat (Fig. 5b). Following p21 overexpression, PCNA and Ki67 were downregulated, but the expression of cyclin D1 was not influenced in hHFMSCs ${ }^{\mathrm{OCT} 4}$ (Fig. 5c, d). The proliferation and colony formation of the cells were suppressed, and the osteogenic differentiation capacity was inhibited with p21 overexpression compared with that of the control (Fig. 5e-g). Moreover, we observed that a gene positively associated with senescence, p16, was also upregulated, and a gene negatively associated with senescence, hTERT, was downregulated (Fig. 5h). Additionally, SA- $\beta$-gal staining was increased when p21 was overexpressed in hHFMSCs ${ }^{\text {OCT4 }}$ (Fig. 5i). Taken together, these data suggest that p21 plays a critical role in the suppression of the stem cell properties of hHFMSCs ${ }^{\text {OCT4 }}$.

\section{Overexpression of OCT4 promotes the transcription of DNMTs and elevates p21 methylation in hHFMSCs}

As the transcriptional level of $\mathrm{p} 21$ is regulated by DNA methylation [27], the expression of DNMTs was quantified in hHFMSCs ${ }^{\text {EGFP }}$ and hHFMSCs ${ }^{\text {OCT4 }}$. DNMT1, DNMT3a, and DNMT3b were upregulated in hHFM $\mathrm{SCs}^{\mathrm{OCT} 4}$ at both the mRNA and protein levels (Fig. 6a). To detect whether the transcriptional factor OCT4 upregulated DNMTs by binding to their promoter regions in hHFMSCs, a ChIP assay was performed (Fig. 6b). This result confirmed that OCT4 interacts with the promoter regions of DNMT1, DNMT3a, and DNMT3b, which may promote the transcription of DNMTs. To illustrate the methylation state of the $\mathrm{p} 21$ promoter region, we performed an MSP assay. As shown in Fig. 6c, the methylation level of the $\mathrm{p} 21$ promoter region was markedly higher, and the amount of the promoter that was not methylated was lower in hHFMSCs ${ }^{\text {OCT4 }}$ than in hHFMSCs ${ }^{\text {EGFP }}$. Taken together, our data support our notion that DNMTs are upregulated in OCT4overexpressing hHFMSCs, which may contribute to the elevated methylation and reduced expression of p21 in the cells.

\section{Inhibition of DNMTs abrogates OCT4-supported stemness in hHFMSCs}

To further characterize the role of DNMTs in the stem cell phenotypes maintained by OCT4 in hHFMSCs, the DNMT inhibitor 5-aza-dC and zebularine were applied to hHFMSCs ${ }^{\text {OCT4 }}$. The administration of 5-aza-dC and zebularine led to a dosage-dependent and time course-associated suppression of DNMT activities (Additional file 1: Figures S3 and S4). More importantly, following the inhibition of DNMTs, p21 was strikingly elevated along with the downregulation of proliferation-associated proteins cyclin D1, PCNA, and Ki67 (Fig. 7a, b). Interestingly, the inhibition of DNMTs with 5-aza-dC modestly downregulated the expression of OCT4 (Fig. 7a), although the nuclear location of OCT4 was not affected by the treatment (Fig. 7b). In addition, we observed that the methylation of the p21 promoter region was downregulated and that the amount of the promoter that was not methylated was upregulated when DNMTs were inhibited in hHFMSCs $^{\text {OCT4 }}$ (Fig. 7c), supporting our conclusion

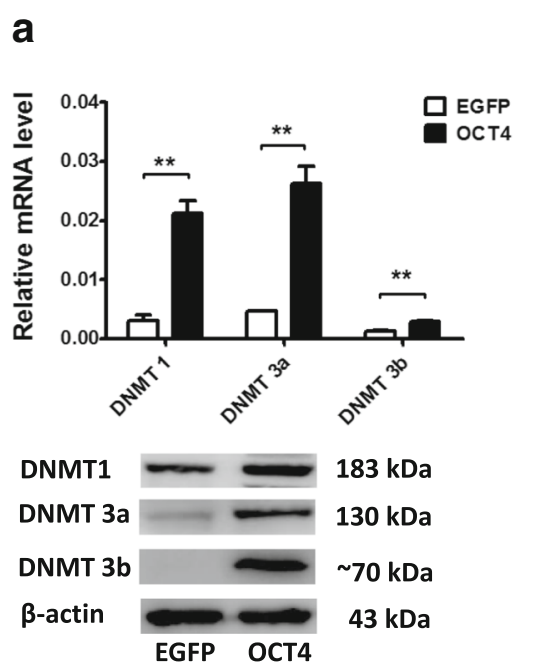

b

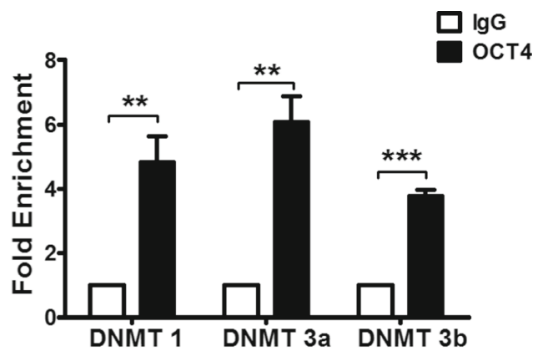

C

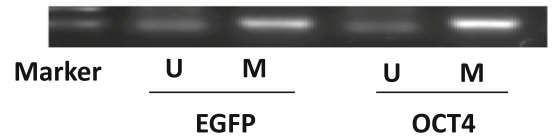

Fig. 6 OCT4 regulates p21 through DNMTs. a qPCR and western blot analyses of the expression levels of DNMT1, DNMT3a, and DNMT3b in hHFMSCs ${ }^{\text {EGFP }}$ and hHFMSCs ${ }^{\text {OCT4 }}$. b ChIP-qPCR of the transcription factor OCT4 and the genes DNMT1, DNMT3a, and DNMT3b. c MSP of p21 in hHFMSCs ${ }^{\text {EGFP }}$ and hHFMSCs ${ }^{\text {OCT4 }}\left({ }^{* *} p<0.01 ;{ }^{* * *} p<0.001\right)$ 


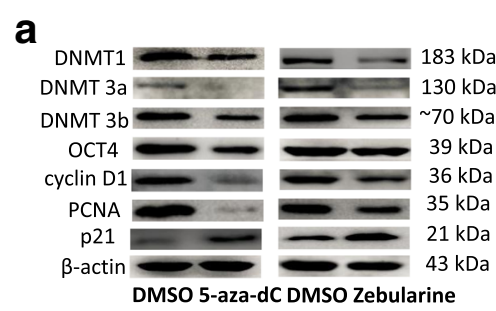

b

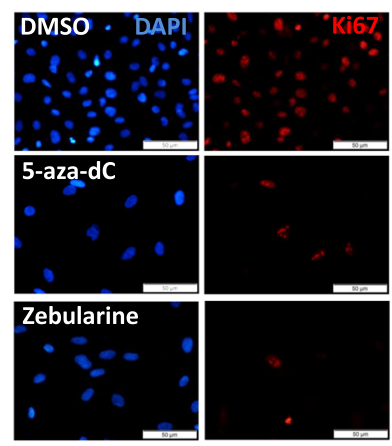

d

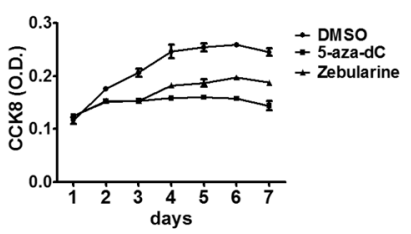

$\mathbf{f}$

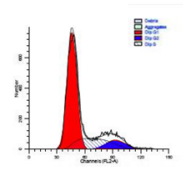

DMSO

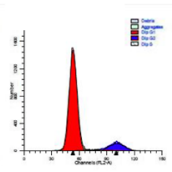

5-aza-dC
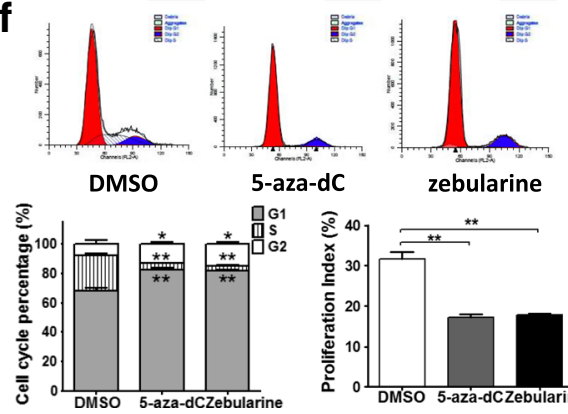
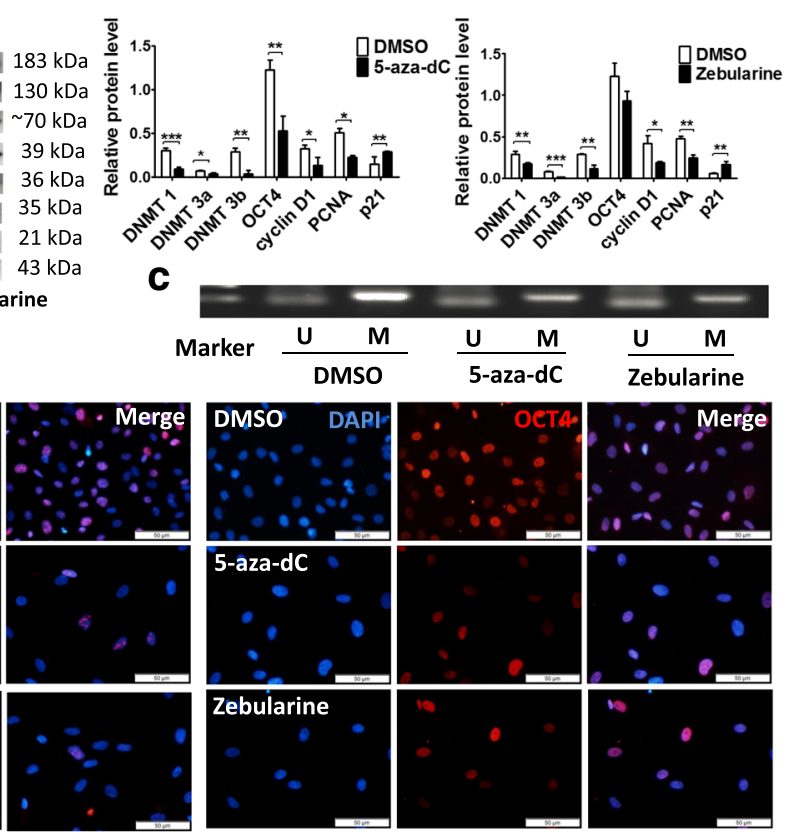

e
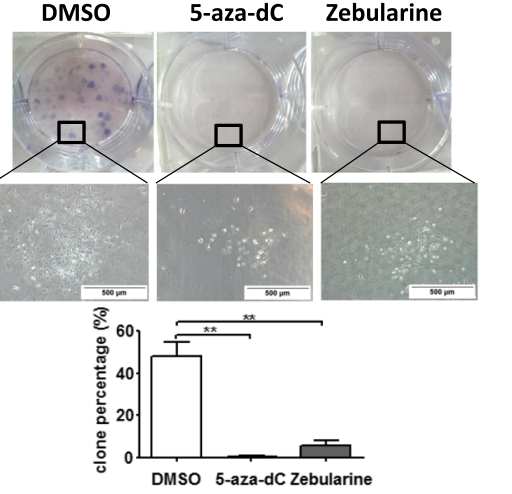

g
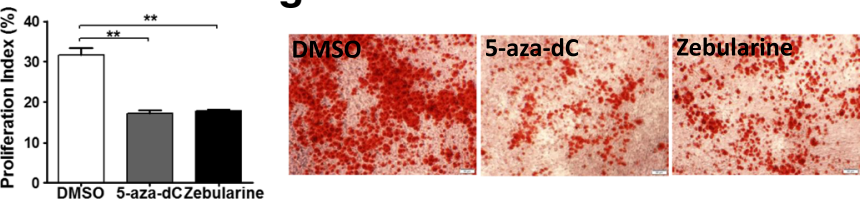

Fig. 7 DNMT inhibition decreased OCT4-increased proliferation capacity and differentiation potential in hHFMSCs. a The impact of 5-aza-dC $(100 \mu \mathrm{M}, 72 \mathrm{~h})$ and zebularine $(100 \mu \mathrm{M}, 48 \mathrm{~h})$ treatment on the expression of DNMTs, p21, OCT4, PCNA, and cyclin D1. b Immunofluorescence of proliferation-associated protein Ki67 (left panels) and OCT4 (right panels) expression and location after DNMT inhibition (bar, 50 m). c MSP of 21 in hHFMSCs ${ }^{\mathrm{OCT} 4}$ treated with DMSO, 5-aza-dC, or zebularine. Cell proliferation curve $(\mathbf{d})$ and clone formation assay (e) after DNMT inhibition; and the enlarged views showed the difference between DMSO and DNMT inhibitor-treated hHFMSCs ${ }^{\mathrm{OCT} 4}$. The histogram is the formation rate of the three clones. $\mathbf{f}$ Effects of DNMT inhibition on hHFMSC cell cycle phase distribution. The percentage of the G1, G2, and S phases in the cell cycle (left of the lower panel) and the PI (right of the lower panel) after DNMT inhibition. "dip" is the abbreviation for diploid. g Osteogenic differentiation after DNMT inhibition. Calcium nodules were detected by Alizarin Red S staining (bar, $50 \mu \mathrm{m}) .\left({ }^{*} p<0.05 ;{ }^{* *} p<0.01\right)$

that the downregulation of $\mathrm{p} 21$ in hHFMSCs ${ }^{\mathrm{OCT} 4}$ was mediated by DNMTs.

As expected, the inhibition of DNMTs led to a reduced proliferative rate (Fig. 7d) and decreased colony formation capacity (Fig. 7e) in hHFMSCs ${ }^{\text {OCT4 }}$. These cells also displayed a G1 phase arrest and a low PI (Fig. 7f). Additionally, the osteogenic differentiation capacity of
hHFMSCs ${ }^{\text {OCT4 }}$ was also blocked due to the exposure to DNMT inhibitors (Fig. 7g). These data suggested that DNMT inhibition suppressed the stem cell properties in hHFMSCs ${ }^{\text {OCT4 }}$. Moreover, genes positively associated with senescence, p21 and p16, were upregulated, and a gene negatively associated with senescence, hTERT, was downregulated by DNMT inhibition in the cells 


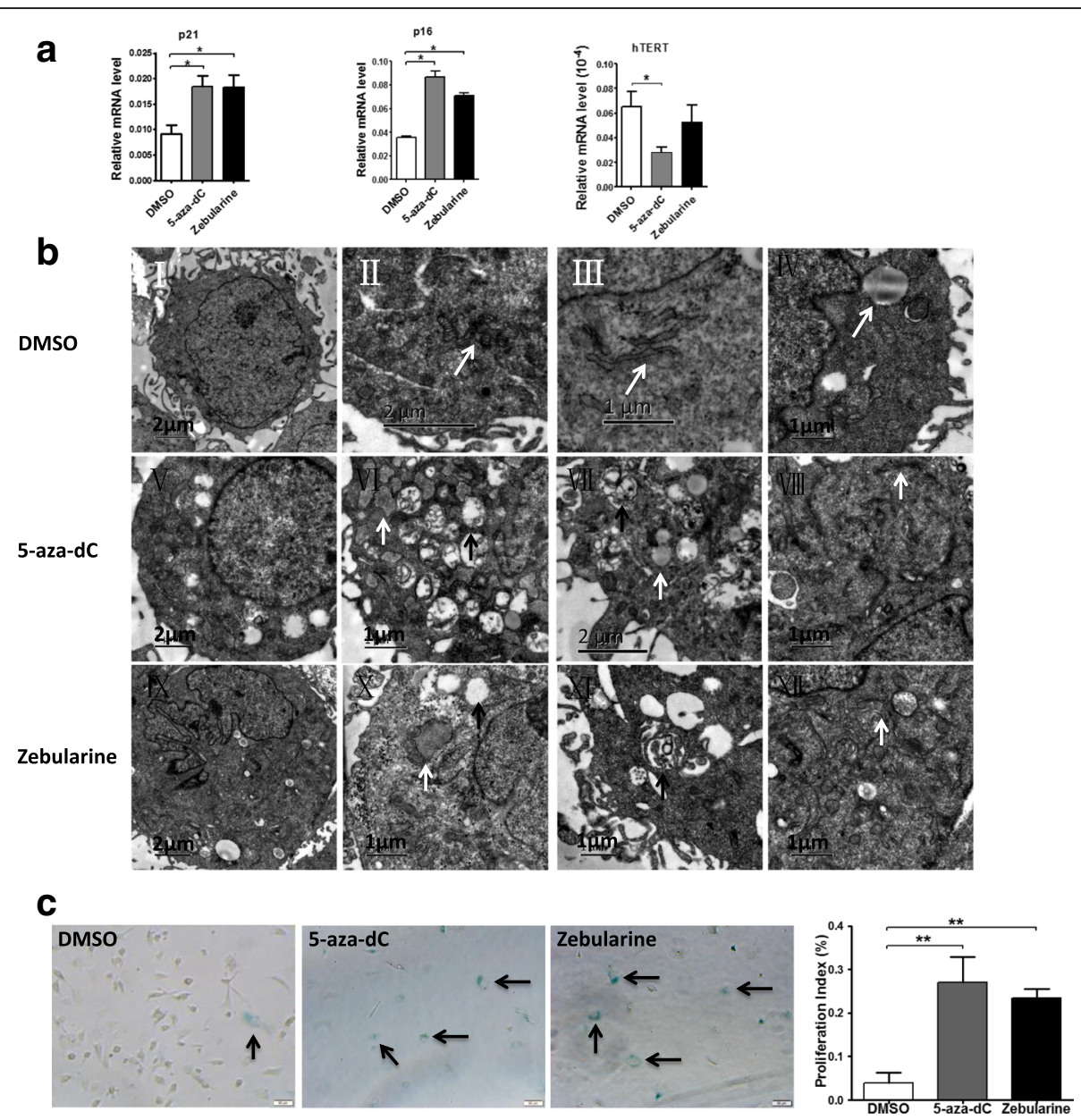

Fig. 8 DNMT inhibition promoted senescence in hHFMSCs. a qPCR results for the expression of senescence-associated genes. $\mathbf{b}$ Effects of DNMT inhibition on hHFMSCs under transmission electron microscopy. (I) Rich microvilli in the cell surface, regularly shaped nuclei, and abundant euchromatin in the nucleus. (II) Normal mitochondria. (III) The cytoplasm rich in rough endoplasmic reticulum. (IV) Some cells containing lipid drops. $(V, I X)$ The microvilli in the cell surface were almost completely removed, and some of the nuclei are irregular in shape. $(V I, X)$ The dilation of the rough endoplasmic reticulum (white arrow) and the turgidity and vacuolization of the mitochondrion (black arrow). (VII, XI) The secondary lysosomes (black arrow) and lipid drops (white arrow) in some cells. (VIII, XII) The contraction of the Golgi body. c SA- $\beta$-gal staining after DNMT inhibition (bar, $50 \mu \mathrm{m})$; stained cells are indicated by arrows. $\left({ }^{*} p<0.05 ;{ }^{* *} p<0.01\right)$

(Fig. 8a). Electron microscopy showed that the cells manifested in a senescent state after DNMT inhibition (Fig. $8 \mathrm{~b}$ ) and that the level of positive SA- $\beta$-gal staining was high when DNMTs were inhibited in hHFMSCs ${ }^{\text {OCT4 }}$ (Fig. 8c). These data suggest that DNMT inhibition promotes hHFMSC senescence.

Thus, we demonstrated that OCT4 regulated hHF MSC self-renewal and senescence through downregulating p21 by DNMTs.

\section{Discussion}

It was reported that the pluripotency gene OCT4 plays a pivotal role in the maintenance of stem cell properties by regulating self-renewal and senescence. Here, we report that OCT4 maintained self-renewal and reversed senescence in hHFMSCs. After the ectopic expressing of
OCT4, we found that OCT4 was localized in the nucleus of hHFMSCs ${ }^{\text {OCT4 }}$. OCT4 promoted cell proliferation and osteogenic differentiation and reversed senescence in hHFMSCs. NGS showed that p21 was downregulated in hHFMSCs ${ }^{\text {OCT4 }}$. KEGG pathway analysis revealed enrichment in the alteration of cell cycle-associated genes. We further demonstrated that OCT4 enhanced the expression of DNMT1, DNMT3a, and DNMT3b through binding to these DNMT promoter regions. Additionally, the overexpression of $\mathrm{p} 21$ or the inhibition of DNMTs abolished the functional role of OCT4 in the maintenance of the stemness of hHFMSCs. Collectively, our data demonstrate that OCT4 was essential for maintaining self-renewal properties and for reversing senescence in hHFMSCs. OCT4 promoted the transcriptional activation of DNMTs and hence elevated the methylation of 
p21, leading to cell cycle progression and suppression of senescence in hHFMSCs.

In previous studies [46, 47], the overexpression or silencing of OCT4 showed similar results, demonstrating that OCT4 can promote cell proliferation capacity. It was reported that OCT4 binds to the promoter region of miR-302a and hence promotes an increase of $S$ phase cells and a decrease of G1 phase cells through cyclin D1 in hESCs [48]. The overexpression of OCT4 and SOX2 could also increase $\mathrm{S}$ phase and decrease G1 phase probably through the upregulation of cyclin D1 in hATMSCs [49]. Similarly, we found that the expression of OCT4 led to an increase in S and G2 phase cells as well as a decrease of G1 phase cells and the upregulation of cyclin D1. Consequently, OCT4 participates in the regulation of the cell cycle, which is a critical process for determining cell proliferation and senescence [50] and is vital to maintaining stem cell properties [51]. In addition, an extended G1 phase may be detrimental to stem cell identity [52]. In the current study, we found that the overexpression of OCT4 improved the osteogenic differentiation capacity, which is consistent with previous studies [53-55]. Moreover, similar to previous studies $[18,56]$, we found that OCT4 prevented hHF MSCs from entering a state of senescence, as evidenced by the expression of senescence-associated markers, morphological alterations in ultrastructure, and SA- $\beta$ gal staining.

OCT4 has been reported previously to drive the expression of a number of pluripotent-specific genes [57]. In the present study, we identified genes regulated by OCT4 using NGS in hHFMSCs. We also determined the enrichment of signaling pathways associated with OCT4 expression in hHFMSCs using GO and KEGG analyses. As a result, the cell cycle pathway was identified. The cell cycle plays a pivotal role in the OCT4-mediated maintenance of the stem cell state. p21, a cyclindependent kinase inhibitor, promotes cell cycle arrest. NGS data showed that $\mathrm{p} 21$ was significantly downregulated in hHFMSCs ${ }^{\mathrm{OCT} 4}$. Previous reports demonstrated that $\mathrm{p} 21$ has a negative impact on stem cell functions $[58,59]$. Therefore, $\mathrm{p} 21$ seems to be an important gene in OCT4-maintained hHFMSC stemness.

Our current data showed that the overexpression of p21 abolished the functional roles of OCT4 in hHF MSCs, except for the expression of cyclin D1. Cyclin D1, when expressed, associates with a cyclin-dependent kinase (CDK) 4 or 6 , and this complex phosphorylates and activates genes whose products regulate the G1/S transition of the cell cycle [23]. The activity of the cyclin D1/ CDK complex is also regulated by $21[22,60]$. Thus, p21 inhibits the activity of the cyclin D1 complex instead of its expression. The upregulation of cyclin D1 in hHFMSCs $^{\text {OCT4 }}$ and the downregulation of the gene after
DNMT treatment may be due to alternative signals. It would be interesting to pursue the exact mechanism of cyclin D1 regulation in hHFMSCs ${ }^{\text {OCT4 }}$ in the future.

DNA methylation is essential during development, resulting in the silencing of early embryonic genes and the activation of the lineage-specific genes that drive cell differentiation [61]. Tissue-specific genes are upregulated in methylation-deficient mESCs [62]. Moreover, methylation is activated in induced pluripotent stem cells (iPSCs) from parental mouse embryonic fibroblasts [63]. Hence, DNMTs play a distinct role in maintaining stem cell properties. DNA methylation changes in aged tissues and cells $[64,65]$, regulates the expression of a certain portion of genes, and partly contributes to the introduction and establishment of senescence [66]. Meanwhile, DNMTs are downregulated along with continuous passage. The current data showed that DNMT inhibition could abolish the functions of OCT4 in hHFMSCs and that OCT4 enhanced the expression of DNMTs through binding to their promoter region. These results support the notion that OCT4 maintains hHFMSC properties through the DNMT-regulated downstream gene $\mathrm{p} 21$.

\section{Conclusions}

In this study, we focused on the role of OCT4 in maintaining hHFMSC properties and found that OCT4 was essential for maintaining self-renewal properties and reversing senescence in hHFMSCs. The mechanism underlying this is that OCT4 could suppress p21, the downstream stem cell property-associated gene, through upregulating DNMTs. These results provide a theoretical basis for hHFMSCs in regenerative medicine and may be beneficial for personalized cell therapy.

\section{Additional files}

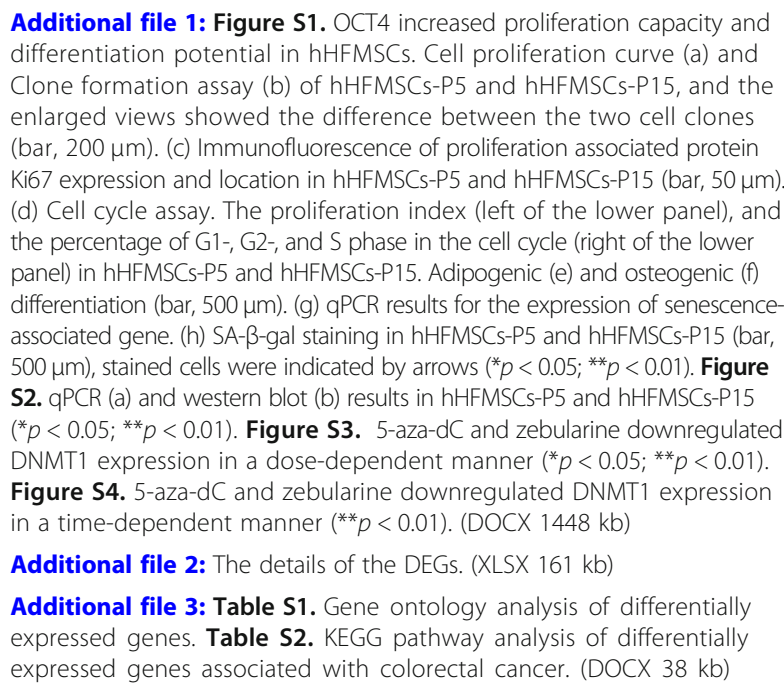

Additional file 1: Figure S1. OCT4 increased proliferation capacity and differentiation potential in hHFMSCs. Cell proliferation curve (a) and Clone formation assay (b) of hHFMSCs-P5 and hHFMSCs-P15, and the enlarged views showed the difference between the two cell clones (bar, $200 \mu \mathrm{m}$ ). (c) Immunofluorescence of proliferation associated protein Ki67 expression and location in hHFMSCs-P5 and hHFMSCs-P15 (bar, $50 \mu \mathrm{m}$ ). (d) Cell cycle assay. The proliferation index (left of the lower panel), and the percentage of G1-, G2-, and S phase in the cell cycle (right of the lower panel) in hHFMSCs-P5 and hHFMSCs-P15. Adipogenic (e) and osteogenic ( $f$ ) differentiation (bar, $500 \mu \mathrm{m})$. (g) qPCR results for the expression of senescenceassociated gene. (h) SA- $\beta$-gal staining in hHFMSCs-P5 and hHFMSCs-P15 (bar, $500 \mu \mathrm{m})$, stained cells were indicated by arrows $\left({ }^{*} p<0.05 ;{ }^{* *} p<0.01\right)$. Figure S2. qPCR (a) and western blot (b) results in hHFMSCs-P5 and hHFMSCs-P15 $\left.{ }^{*} p<0.05 ;{ }^{* *} p<0.01\right)$. Figure S3. 5-aza-dC and zebularine downregulated DNMT1 expression in a dose-dependent manner $\left({ }^{*} p<0.05 ;{ }^{* *} p<0.01\right.$ ). Figure S4. 5-aza-dC and zebularine downregulated DNMT1 expression in a time-dependent manner (**$p<0.01)$. (DOCX $1448 \mathrm{~kb}$ )

Additional file 2: The details of the DEGs. (XLSX $161 \mathrm{~kb}$ )

Additional file 3: Table S1. Gene ontology analysis of differentially expressed genes. Table S2. KEGG pathway analysis of differentially expressed genes associated with colorectal cancer. (DOCX 38 kb) 


\section{Abbreviations}

7AAD: 7-Amino actinomycin; bFGF: Basic fibroblast growth factor; CDK: Cyclindependent kinase; ChIP: Chromatin immunoprecipitation; DEGs: Differentially expressed genes; DMSO: Dimethyl sulfoxide; DNMT1: DNA methyltransferase 1; DNMT3a: DNA methyltransferase 3 alpha; DNMT3b: DNA methyltransferase 3 beta; DNMTs: DNA methyltransferases; ESCs: Embryonic stem cells; FBS: Fetal bovine serum; hHFMSCs: Human hair follicle mesenchymal stem cells; hHFMSCs ${ }^{\text {EGFP: }}$ hHFMSCs transfected with scrambled lentivirus; hHFMSCs ${ }^{\text {OCT4 }}$ : hHFMSCs transfected with lentivirus encoding the OCT4; hTERT: Human telomerase catalytic subunit; iPSCs: Induced pluripotent stem cells; KEGG: Kyoto Encyclopedia of Genes and Genomes; MSCs: Mesenchymal stem cells; MSP: Methylation-specific PCR; NGS: Next-generation sequencing; PCNA: Proliferating cell nuclear antigen; PI: Proliferation index; SA- $\beta$-gal: Senescence-associated $\beta$-galactosidase; TFs: Transcription factors

\section{Acknowledgements}

We would like to thank Shijiang Lu, Advanced Cell Technology, USA, for critical review and editing of the manuscript.

\section{Funding}

The study was supported by Industrial Technology Research and Development Program in Jilin Province of China (Code (2011) 1225).

\section{Availability of data and materials}

All data generated or analyzed during this study are included in this published article.

\section{Authors' contributions}

The study was designed by CQ and YLi. YLu carried out most of the experiments, performed the statistical analysis, and drafted the manuscript. HQ carried out some of the experiments. DQ and WX helped with the statistical analysis. SL helped with the editing of the paper. XJ, PS, YG, YJ, and XW assisted with the experiments. All authors have read and approved the final manuscript.

\section{Ethics approval and consent to participate}

All experiments were approved by the Jilin University Hospital, Jilin University Ethics Committee (No. 2011037). hHFMSCs were collected from donors with written informed consent in accordance with guidelines of the ethics committee of the Jilin University Hospital.

\section{Consent for publication}

Not applicable.

\section{Competing interests}

The authors declare that they have no competing interests.

\section{Publisher's Note}

Springer Nature remains neutral with regard to jurisdictional claims in published maps and institutional affiliations.

\section{Author details}

${ }^{1}$ The Key Laboratory of Pathobiology, Ministry of Education, Department of Pathology, College of Basic Medical Sciences, Jilin University, 126 Xinmin Avenue, Changchun 130021, China. ${ }^{2}$ Cell Processing Section, Department of Transfusion, Clinical Center, National Institutes of Health, Bethesda, MD 20892, USA. ${ }^{3}$ Department of Cellular and Molecular Medicine, University of California, San Diego, CA 92093-0651, USA.

Received: 26 August 2018 Revised: 11 December 2018 Accepted: 20 December 2018 Published online: 15 January 2019

\section{References}

1. Paus R, Cotsarelis G. The biology of hair follicles. N Engl J Med. 1999;341(7): 491-7.

2. Morris RJ, et al. Capturing and profiling adult hair follicle stem cells. Nat Biotechnol. 2004;22(4):411-7.

3. Wang $Y$, et al. Induced pluripotent stem cells from human hair follicle mesenchymal stem cells. Stem Cell Rev. 2013;9(4):451-60.

4. Jahoda CA, et al. Smooth muscle alpha-actin is a marker for hair follicle dermis in vivo and in vitro. J Cell Sci. 1991;99(Pt 3):627-36.
5. Chen $X$, et al. Integration of external signaling pathways with the core transcriptional network in embryonic stem cells. Cell. 2008;133(6):1106-17.

6. Kim J, et al. An extended transcriptional network for pluripotency of embryonic stem cells. Cell. 2008;132(6):1049-61.

7. Ding J, et al. Oct4 links multiple epigenetic pathways to the pluripotency network. Cell Res. 2012;22(1):155-67.

8. Jaenisch R, Young R. Stem cells, the molecular circuitry of pluripotency and nuclear reprogramming. Cell. 2008;132(4):567-82.

9. Nichols J, et al. Formation of pluripotent stem cells in the mammalian embryo depends on the POU transcription factor Oct4. Cell. 1998;95(3):379-91.

10. Darr H, Mayshar Y, Benvenisty N. Overexpression of NANOG in human ES cells enables feeder-free growth while inducing primitive ectoderm features. Development. 2006;133(6):1193-201.

11. Niwa H, Miyazaki J, Smith AG. Quantitative expression of Oct-3/4 defines differentiation, dedifferentiation or self-renewal of ES cells. Nat Genet. 2000; 24(4):372-6.

12. Hay DC, et al. Oct-4 knockdown induces similar patterns of endoderm and trophoblast differentiation markers in human and mouse embryonic stem cells. Stem Cells. 2004:22(2):225-35.

13. Matin MM, et al. Specific knockdown of Oct4 and beta2-microglobulin expression by RNA interference in human embryonic stem cells and embryonic carcinoma cells. Stem Cells. 2004;22(5):659-68.

14. Wang J, et al. A protein interaction network for pluripotency of embryonic stem cells. Nature. 2006;444(7117):364-8.

15. Kashyap $\mathrm{V}$, et al. Regulation of stem cell pluripotency and differentiation involves a mutual regulatory circuit of the NANOG, OCT4, and SOX2 pluripotency transcription factors with polycomb repressive complexes and stem cell microRNAs. Stem Cells Dev. 2009:18(7):1093-108.

16. Rodda DJ, et al. Transcriptional regulation of nanog by OCT4 and SOX2. J Biol Chem. 2005;280(26):24731-7.

17. Masui $\mathrm{S}$, et al. Pluripotency governed by Sox2 via regulation of Oct3/4 expression in mouse embryonic stem cells. Nat Cell Biol. 2007:9(6):625-35.

18. Piccinato CA, et al. High OCT4 and low p16(INK4A) expressions determine in vitro lifespan of mesenchymal stem cells. Stem Cells Int. 2015;2015:369828.

19. Lee J, et al. Oct-4 controls cell-cycle progression of embryonic stem cells. Biochem J. 2010;426(2):171-81.

20. Burdon T, Smith A, Savatier P. Signalling, cell cycle and pluripotency in embryonic stem cells. Trends Cell Biol. 2002;12(9):432-8.

21. Ghule PN, et al. Reprogramming the pluripotent cell cycle: restoration of an abbreviated G1 phase in human induced pluripotent stem (iPS) cells. J Cell Physiol. 2011;226(5):1149-56.

22. Sherr CJ. The Pezcoller lecture: cancer cell cycles revisited. Cancer Res. 2000; 60(14):3689-95.

23. Sherr CJ, Roberts JM. CDK inhibitors: positive and negative regulators of G1phase progression. Genes Dev. 1999;13(12):1501-12.

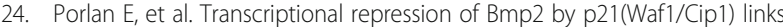
quiescence to neural stem cell maintenance. Nat Neurosci. 2013;16(11): $1567-75$.

25. Lee J, et al. Runx1 and p21 synergistically limit the extent of hair follicle stem cell quiescence in vivo. Proc Natl Acad Sci U S A. 2013;110(12):4634-9.

26. Yew TL, et al. Knockdown of p21(Cip1/Waf1) enhances proliferation, the expression of stemness markers, and osteogenic potential in human mesenchymal stem cells. Aging Cell. 2011;10(2):349-61.

27. Fang JY, Lu YY. Effects of histone acetylation and DNA methylation on p21( WAF1) regulation. World J Gastroenterol. 2002;8(3):400-5.

28. Bogdanovic O, Lister R. Of mice and man: differential DNMT dependence in mammalian ESCs. Cell Stem Cell. 2015;16(5):459-60.

29. Bird A. DNA methylation patterns and epigenetic memory. Genes Dev. 2002;16(1):6-21.

30. Nawy T. Dynamics of DNA demethylation. Nat Methods. 2013;10(6):466

31. Liao J, et al. Targeted disruption of DNMT1, DNMT3A and DNMT3B in human embryonic stem cells. Nat Genet. 2015;47(5):469-78.

32. Chen $\mathrm{T}$, et al. Establishment and maintenance of genomic methylation patterns in mouse embryonic stem cells by Dnmt3a and Dnmt3b. Mol Cell Biol. 2003:23(16):5594-605.

33. Tsumura A, et al. Maintenance of self-renewal ability of mouse embryonic stem cells in the absence of DNA methyltransferases Dnmt1, Dnmt3a and Dnmt3b. Genes Cells. 2006;11(7):805-14.

34. Li E. Chromatin modification and epigenetic reprogramming in mammalian development. Nat Rev Genet. 2002;3(9):662-73. 
35. Liu Z, et al. Transdifferentiation of human hair follicle mesenchymal stem cells into red blood cells by OCT4. Stem Cells Int. 2015;2015:389628.

36. Li B, Dewey CN. RSEM: accurate transcript quantification from RNA-Seq data with or without a reference genome. BMC Bioinformatics. 2011;12:323.

37. Robinson MD, McCarthy DJ, Smyth GK. edgeR: a Bioconductor package for differential expression analysis of digital gene expression data. Bioinformatics. 2010;26(1):139-40.

38. Dennis G Jr, et al. DAVID: Database for Annotation, Visualization, and Integrated Discovery. Genome Biol. 2003;4(5):P3.

39. Flores I, Blasco MA. The role of telomeres and telomerase in stem cell aging FEBS Lett. 2010;584(17):3826-30.

40. Patel PL, et al. Derepression of hTERT gene expression promotes escape from oncogene-induced cellular senescence. Proc Natl Acad Sci U S A 2016;113(34):E5024-33.

41. Brugarolas J, et al. Radiation-induced cell cycle arrest compromised by p21 deficiency. Nature. 1995;377(6549):552-7.

42. Kamijo T, et al. Tumor suppression at the mouse INK4a locus mediated by the alternative reading frame product p19ARF. Cell. 1997;91(5):649-59.

43. Lu Y, et al. The cytotoxic effects of bile acids in crude bile on human pancreatic cancer cell lines. Surg Today. 2000;30(10):903-9.

44. Hill SM, Blask DE. Effects of the pineal hormone melatonin on the proliferation and morphological characteristics of human breast cancer cells (MCF-7) in culture. Cancer Res. 1988;48(21):6121-6.

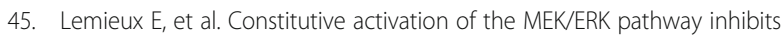
intestinal epithelial cell differentiation. Am J Physiol Gastrointest Liver Physiol. 2011;301(4):G719-30.

46. Liu TM, et al. Effects of ectopic Nanog and Oct4 overexpression on mesenchymal stem cells. Stem Cells Dev. 2009;18(7):1013-22.

47. Seo KW, et al. OCT4A contributes to the stemness and multi-potency of human umbilical cord blood-derived multipotent stem cells (hUCB-MSCs). Biochem Biophys Res Commun. 2009;384(1):120-5.

48. Card DA, et al. Oct4/Sox2-regulated miR-302 targets cyclin D1 in human embryonic stem cells. Mol Cell Biol. 2008;28(20):6426-38.

49. Han SM, et al. Enhanced proliferation and differentiation of Oct4- and Sox2overexpressing human adipose tissue mesenchymal stem cells. Exp Mol Med. 2014;46:e101.

50. Yoon DS, et al. Importance of Sox2 in maintenance of cell proliferation and multipotency of mesenchymal stem cells in low-density culture. Cell Prolif. 2011:44(5):428-40.

51. Schoeftner S, et al. An Oct4-pRb axis, controlled by MiR-335, integrates stem cell self-renewal and cell cycle control. Stem Cells. 2013;31(4):717-28.

52. Hatfield SD, et al. Stem cell division is regulated by the microRNA pathway. Nature. 2005;435(7044):974-8.

53. Fan $Y X$, et al. Oct4 and Sox2 overexpression improves the proliferation and differentiation of bone mesenchymal stem cells in Xiaomeishan porcine. Genet Mol Res. 2013;12(4):6067-79.

54. Li HL, et al. miR-302 regulates pluripotency, teratoma formation and differentiation in stem cells via an AKT1/OCT4-dependent manner. Cell Death Dis. 2016;7:e2078.

55. Yu KR, et al. CD49f enhances multipotency and maintains stemness through the direct regulation of OCT4 and SOX2. Stem Cells. 2012;30(5):876-87.

56. Kim JH, et al. Regulation of adipose tissue stromal cells behaviors by endogenic Oct4 expression control. PLoS One. 2009;4(9):e7166.

57. Rizzino A. Concise review: the Sox2-Oct4 connection: critical players in a much larger interdependent network integrated at multiple levels. Stem Cells. 2013;31(6):1033-9.

58. Choudhury AR, et al. Cdkn1a deletion improves stem cell function and lifespan of mice with dysfunctional telomeres without accelerating cancer formation. Nat Genet. 2007;39(1):99-105

59. Kawamura T, et al. Linking the p53 tumour suppressor pathway to somatic cell reprogramming. Nature. 2009;460(7259):1140-4.

60. Dotto GP. p21(WAF1/Cip1): more than a break to the cell cycle? Biochim Biophys Acta. 2000;1471(1):M43-56.

61. Xie $W$, et al. Epigenomic analysis of multilineage differentiation of human embryonic stem cells. Cell. 2013;153(5):1134-48.

62. Fouse SD, et al. Promoter CpG methylation contributes to ES cell gene regulation in parallel with Oct4/Nanog, PcG complex, and histone H3 K4/ K27 trimethylation. Cell Stem Cell. 2008;2(2):160-9.

63. Fernandez-Arroyo $\mathrm{S}$, et al. Activation of the methylation cycle in cells reprogrammed into a stem cell-like state. Oncoscience. 2015;2(12):958-67.
64. Kaneda A, et al. Activation of Bmp2-Smad1 signal and its regulation by coordinated alteration of H3K27 trimethylation in Ras-induced senescence. PLoS Genet. 2011;7(11):e1002359.

65. Horvath $\mathrm{S}$, et al. Aging effects on DNA methylation modules in human brain and blood tissue. Genome Biol. 2012;13(10):R97.

66. Sakaki $M$, et al. Potential roles of DNA methylation in the initiation and establishment of replicative senescence revealed by array-based methylome and transcriptome analyses. PLoS One. 2017;12(2):e0171431.
Ready to submit your research? Choose BMC and benefit from:

- fast, convenient online submission

- thorough peer review by experienced researchers in your field

- rapid publication on acceptance

- support for research data, including large and complex data types

- gold Open Access which fosters wider collaboration and increased citations

- maximum visibility for your research: over $100 \mathrm{M}$ website views per year

At BMC, research is always in progress.

Learn more biomedcentral.com/submissions 